\title{
cDNA microarray analysis of non-selected cases of acute myeloid leukemia demonstrates distinct clustering independent of cytogenetic aberrations and consistent with morphological signs of differentiation
}

\author{
ANNE MARGRETE $Ø$ YAN $^{1,2}$, TROND HELLEM B $\varnothing^{2-4}$, INGE JONASSEN ${ }^{3,4}$, BJØRN TORE GJERTSEN ${ }^{5,6}$, \\ ØYSTEIN BRUSERUD ${ }^{5,6}$ and KARL-HENNING KALLAND ${ }^{1,2}$
}

\author{
${ }^{1}$ Department of Microbiology and Immunology, Haukeland University Hospital; ${ }^{2}$ The Gade Institute, ${ }^{3}$ Department of \\ Informatics, University of Bergen; ${ }^{4}$ Computational Biology Unit, Bergen Center for Computational Science, University of \\ Bergen; ${ }^{5}$ Section of Hematology, Haukeland University Hospital; ${ }^{6}$ Institute of Medicine, University of Bergen, Bergen, Norway
}

Received November 8, 2005; Accepted December 27, 2005

\begin{abstract}
Acute myeloid leukemia (AML) is a heterogeneous disease with respect to biology and clinical course. Until now the basis for prognostic evaluation and therapeutic decision has been the karyotype, genetic FLT3 abnormalities and the initial chemotherapy response. A question that has emerged is if extensive gene expression analysis may supplement or partly replace current diagnostics. In an attempt to address this question, we performed cDNA microarray analysis on peripheral blood samples of 25 patients with newly diagnosed AML with high blast counts. The patients were randomly selected from a large group of consecutive patients. Leaveone-out crossvalidation (LOOCV) showed with high accuracy that gene expression classifiers could predict if leukaemia samples belonged to the FAB AML-M1 or to the FAB AMLM2 groups. An unsupervised two-dimensional hierarchical cluster analysis generated 3 patient subgroups. Except for an accumulation of samples classified as FAB M1 and M2 in cluster 3, there was no evident relationship between the clusters and the FAB classification. Each subgroup displayed clearly distinguished gene expression patterns validated using realtime quantitative PCR analysis. The identification of specific gene expressions that together constitute regulatory modules must complement cluster analyses in order to achieve an accurate basis for prognosis and prediction.
\end{abstract}

Correspondence to: Dr Anne Margrete Øyan, Department of Microbiology and Immunology, The Gade Institute, Haukeland University Hospital, Centre for Research in Virology, BBB, Jonas Lies v. 91, N-5009 Bergen, Norway

E-mail: anne.oyan@gades.uib.no

Key words: acute myeloid leukemia, cDNA microarray, gene expression, differentiation

\section{Introduction}

Acute myeloid leukaemia (AML) is an aggressive malignant disorder characterized by accumulation of immature myeloid progenitors in the bone marrow (1). AML can be divided into a heterogeneous majority and the less frequent acute promyelocytic leukaemia (APL) variant characterized by promyelocyte accumulation, chromosomal translocations involving 17q21, susceptibility to differentiation induction and good prognosis (2). The major prognostic parameters for non-APL variants are response to the initial chemotherapy cycle and the genetic abnormalities of the malignant cells $(3,4)$. However, several prognostically important genetic abnormalities are associated with specific signs of differentiation in the malignant cells [e.g. inv(16); $t(8 ; 21)]$, suggesting that molecular mechanisms involved in regulation of differentiation may also contribute to the prognostic impact of these abnormalities (5). Recent DNA microarray studies suggest that AML classification can be further improved in terms of distinguishing AML from acute lymphoblastic leukaemia (ALL) (6-8), defining acute leukemias with MLL-abnormalities as a possible new entity separate from AML and ALL (9) and identifying new subgroups of AML with specific patterns of gene expression $(10,11)$. Specific gene expression patterns are associated with prognostically important genetic abnormalities [i.e. $\mathrm{t}(8 ; 21)$, inv16, $\mathrm{t}(8 ; 21), \mathrm{t}(15 ; 17), 11 \mathrm{q} 23$-aberrations] (12-14). Prognostic molecular markers have also been found in AML blasts with normal cytogenetics $(15,16)$.

Several new therapeutic approaches are now considered in AML, including differentiation induction through inhibitors of intracellular signaling and drugs targeting gene transcription (17). In a recent article, we emphasised the importance of collecting biological material as a part of future populationbased clinical studies of AML, and at least two approaches are possible for integration of DNA microarray analysis in future clinical studies (18). Firstly, microarrays may be used to monitor effects of treatment, e.g. the effects of differentiationinduced therapy or therapeutic approaches targeting gene transcripts. This may imply patterns associated with the 
Table I. Clinical and biological characteristics of acute myeloid leukemia patients.

\begin{tabular}{|c|c|c|c|c|c|c|c|c|c|c|c|c|c|}
\hline Pts. & Sex & Age & Previous & FAB & Non-supervised & Men & nbrane $\mathrm{r}$ & holecule & express & ion $^{\mathrm{a}}$ & Cytogenetic & FLT3 & WBC \\
\hline & & & malignant disease & classification & AML cluster ${ }^{d}$ & $\mathrm{CD} 13$ & $\mathrm{CD} 14$ & $\mathrm{CD} 15$ & $\mathrm{CD} 33$ & CD34 & abnormality & abnormality ${ }^{\mathrm{b}}$ & counts $^{\mathrm{c}}$ \\
\hline 0043 & $\mathrm{~F}$ & 64 & & AML-M1 & $\mathrm{C} 1$ & + & - & $\mathrm{nt}$ & - & - & Normal & - & 84 \\
\hline 0041 & $\mathrm{~F}$ & 48 & & AML-M1 & $\mathrm{C} 3$ & + & - & - & + & + & $\operatorname{del}(7)(q 22)$ & ITD & 30 \\
\hline 0050 & M & 64 & MDS & AML-M1 & $\mathrm{C} 3$ & + & - & + & + & + & $37-46 X Y$ & D835 & 12 \\
\hline 0047 & M & 30 & & AML-M1 & $\mathrm{C} 1$ & - & - & $\mathrm{nt}$ & + & - & Normal & - & 78 \\
\hline 0048 & $\mathrm{~F}$ & 54 & Breast cancer & AML-M1 & $\mathrm{C} 3$ & + & - & $\mathrm{nt}$ & + & + & $\mathrm{nt}$ & ITD & 35 \\
\hline 0033 & $\mathrm{~F}$ & 63 & & AML-M1 & $\mathrm{C} 3$ & + & - & + & - & + & $\mathrm{nt}$ & - & 76 \\
\hline 0031 & M & 83 & & AML-M2 & Outgroup & + & - & $\mathrm{nt}$ & + & + & nt & - & 49 \\
\hline 0032 & $\mathrm{~F}$ & 45 & & AML-M2 & $\mathrm{C} 2$ & + & - & - & + & - & Normal & ITD, D835 & 123 \\
\hline 0034 & $\mathrm{~F}$ & 52 & & AML-M2 & $\mathrm{C} 3$ & + & - & $\mathrm{nt}$ & + & + & Normal & - & 58 \\
\hline 0036 & $\mathrm{~F}$ & 51 & & AML-M2 & $\mathrm{C} 1$ & + & - & + & + & - & Normal & ITD, wt ${ }^{-}$ & 154 \\
\hline 0040 & M & 77 & Hodgkin's disease & AML-M2 & Outgroup & + & - & - & + & + & $\operatorname{del}(7),-20$ & ITD & 62 \\
\hline 0049 & $\mathrm{~F}$ & 58 & & AML-M2 & $\mathrm{C} 3$ & + & - & + & + & - & Normal & ITD, wt & 41 \\
\hline 0008 & $\mathrm{~F}$ & 64 & & AML-M4 & $\mathrm{C} 2$ & - & - & + & + & + & Normal & - & 123 \\
\hline 0024 & M & 29 & & AML-M4 & Outgroup & + & - & + & + & + & Normal & ITD, D835 & 19 \\
\hline 0038 & $\mathrm{~F}$ & 38 & & AML-M4 & $\mathrm{C} 1$ & - & + & + & + & - & Normal & - & 228 \\
\hline 0037 & $\mathrm{~F}$ & 45 & Ovary carcinoma & AML-M4 & $\mathrm{C} 2$ & + & - & + & + & - & Normal & - & 70 \\
\hline 0051 & M & 81 & MDS & AML-M4 & Outgroup & - & + & $\mathrm{nt}$ & - & - & $\mathrm{nt}$ & - & 61 \\
\hline 0023 & $\mathrm{~F}$ & 78 & & AML-M4-5 & $\mathrm{C} 1$ & + & + & - & + & - & $-4-5,+\operatorname{der}(8) \mathrm{T}(8 ; ?)$ & - & 93 \\
\hline 0025 & M & 64 & & AML-M4-5 & $\mathrm{C} 2$ & + & - & - & + & + & Normal & ITD, wt & 135 \\
\hline 0007 & $\mathrm{M}$ & 82 & & AML-M5 & $\mathrm{C} 1$ & + & + & + & + & - & $45 \mathrm{X}$ & - & 198 \\
\hline 0027 & $\mathrm{~F}$ & 75 & & AML-M5 & $\mathrm{C} 1$ & + & - & + & + & + & Normal & ITD & 104 \\
\hline 0035 & $\mathrm{~F}$ & 34 & & AML-M5 & $\mathrm{C} 1$ & - & - & + & + & - & $\mathrm{t}(9 ; 11)(\mathrm{p} 22 ; \mathrm{q} 23)$ & D835 & 286 \\
\hline 0045 & $\mathrm{~F}$ & 58 & & AML-M5 & $\mathrm{C} 1$ & - & + & + & + & - & $\begin{array}{c}\mathrm{t}(2 ; 3)(\mathrm{q} 37 ; \mathrm{q} 21) \\
\mathrm{t}(2 ; 4 ; 10)(\mathrm{q} 13 ; \\
\mathrm{q} 21) \mathrm{q} 21) \\
\operatorname{der}(11 \mathrm{q}), 19 \mathrm{q}+\end{array}$ & - & 58 \\
\hline 0044 & $\mathrm{M}$ & 33 & & AML-M5 & $\mathrm{C} 1$ & + & - & + & + & - & Normal & ITD & 131 \\
\hline 0046 & $\mathrm{~F}$ & 71 & & AML-M5 & $\mathrm{C} 2$ & + & + & + & + & - & Normal & D835 & 64 \\
\hline
\end{tabular}

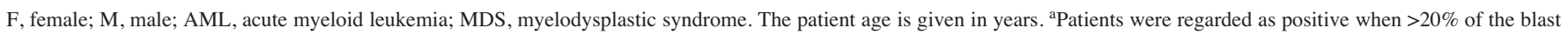

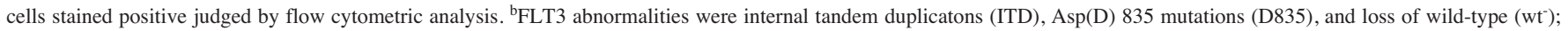
nt, not tested. ${ }^{c}$ White blood cell (WBC) counts in peripheral blood are expressed as x $10^{9} / 1$ (normal range $\left.3.5-10.5 \times 10^{9} / 1\right)$. The WBC included at least $80 \%$ leukemia blasts.

various morphologically defined subsets within both the French-American-British (FAB) and the more recent World Health Organization classification $(5,19)$. Secondly, the experience from highdose cytarabine therapy has demonstrated how the genetic characteristics of malignant cells can be used for prognostic classification of AML patients (20). DNA microarray analysis may then represent an additional approach for identification of new subsets with different responses to therapy. In the present study, we have therefore investigated native AML blasts derived from 25 patients by DNA microarray analysis. Patients were randomly selected from a larger consecutive group (21), and sample collection as well as RNA preparation were highly standardized (18). Despite considerable patient heterogeneity, the DNA microarray analysis allowed us to: i) identify differentiationassociated gene expression patterns; and ii) classify the patients into three major subgroups with abnormalities in the expression of genes involved in intercellular signalling, intracellular signaling, regulation of transcription, and tyrosine kinaseassociated signaling using unsupervised hierarchical cluster analysis.

\section{Materials and methods}

Patient materials. The study was approved by the local Ethics Committee and samples collected after informed consent. During the time period of 1991-2001 we collected peripheral blood AML blasts from 64 consecutive patients with high blood blast counts (21). Cytogenetic analysis was performed for the last 48 of these 64 patients; 28 patients had a normal karyotype, 3 patients had a favourable [all inv(16)] and 5 had an unfavourable karyotype according to the definitions used $(3,4)$. A total of 98 patients with AML were admitted to our institution during the same time period. A similar karyotype distribution was also observed for the whole patient group (the last 73 of the 98 patients examined, 6 patients having a 
favorable karyotype). We investigated AML blasts derived from 25 patients (Table I; median age 58 years with variation range $29-83$ years) that were randomly selected from the 64 consecutive patients with high peripheral blood blast counts (21). According to the FAB classification patients were classified as AML-M0/M1 (undifferentiated, 6 patients), AMLM2 (neutrophil differentiation, 6 patients) and AML-M4/M5 (monocyte differentiation, 13 patients). One ALL sample was included as a test sample.

Preparation of AML blast. Peripheral blood samples were collected on glass tubes (sample tubes with acidum cotrosedextrose solution A; Becton-Dickinson) and leukemic peripheral blood mononuclear cells (PBMC) were isolated by density gradient separation (Ficoll-Hypaque specific density 1.077; NycoMed, Oslo, Norway;) immediately after sampling. We selected patients with a high percentage of AML blasts among the blood leukocytes (Table I), and highly enriched AML cell populations could therefore be prepared by density gradient separation alone ( $>95 \%$ blast cells judged by light microscopy). Cells were frozen without delay and stored frozen in liquid nitrogen (22). Cells were thawed and RNA prepared according to strictly standardized procedures (18).

Microarray analysis. Total RNA was extracted according to standard protocols (23). Synthesis of T7 RNA polymerase promoter-containing double-stranded cDNA and the generation of T7 RNA polymerase amplified RNA (cRNA) were performed as previously described (18) and according to the manufacturer's instructions (Ambion). Aminoallyl-dUTP incorporation followed by cross-coupling of Amersham Cy5- and Cy3-NHS esters was used for fluorochrome labeling of nucleic acids (18). AML sample cRNAs and the referance cRNAs made out of a pool of 18 different cell lines (Supplementary Table I) were labelled with Cy5 and Cy3, respectively.

The Human 1 cDNA Microarray system from Agilent containing 12.814 cDNA clones selected from the Incyte collection was used for the detection of gene expression in the AML samples. Hybridization and washing of the arrays were performed as recommended by Agilent (cDNA Microarray Kit Protocol). An Axon scanner recorded signal intensities at 532- and 633-nm laser lines, and the GenePix Pro software was used for feature extraction and creation of the GenePix intensity report file.

Normalization and analysis of DNA microarray data. After subtraction of background intensities for each spot, missing signals were floored using the value of 20 . This procedure may include potentially interesting genes, i.e. genes that are detectably expressed only for a subset of patients, and we therefore performed data preparation using this method. The flooring of missing signals allowed us to produce log ratios for all spots, including those spots where the signal was only present in one channel. The resulting intensities were again subjected to the intra-array normalization procedure lowess and a gene expression data matrix was produced (24). The lowess method (25) was used to correct for dye-specific effects and log-ratios calculated producing a data matrix with one row per spot (gene) and one column per sample (array). We calculated each gene's two-sample t-score in one FAB class versus the other FAB classes, thereby identifying genes most consistently high or low in one FAB class relative to the other samples. P-values corresponding to the t-scores were found using the t-distribution with n-2 degrees of freedom, where $n$ is the number of samples included in the calculation.

Crossvalidation, validation using permutation test and twoway cluster analysis. We used a leave-one-out crossvalidation (LOOCV) with the diagonal linear discriminant (DLD) (26) approach to test whether it is possible to predict FAB class M1, M2, M4, and M5 from the gene expression data. In this analysis, the samples labelled M4-5 were excluded. Each class was treated separately and we evaluated whether a classifier could be learnt that discriminates this one class from the others. In LOOCV, one sample (patient) is held back, a classifier is learnt using data on the remaining training samples and tested on the held back sample. This procedure is repeated with each patient as test sample and the prediction accuracy is the percentage of (held back) samples that are correctly classified. In this way, we obtained prediction accuracies for each FAB class. For each class, a permutation test was performed (1000 permutations of FAB labels followed by LOOCV) to assess whether an equally good accuracy could be obtained by chance.

The gene expression differences in AML samples between FAB classes M1, M2, M4 and M5 were visualized by taking the genes with the highest t-scores for each class as input to a two-way hierarchical cluster analysis using the J-Express Pro software (www.molmine.com) (27). We also included the two samples belonging to the AML FAB class M4-5 in the two-way cluster analysis to visualize their distribution compared to the other FAB classes.

Unsupervised cluster analysis. In order to explore possible new subtypes by analysis of the expression data, we performed an unsupervised hierarchical clustering of the 25 AML samples. For this, we selected genes with the highest variance among the AML blasts. Before clustering using J-Express Pro, the expression profile of each gene was centered by subtracting the mean over all samples for that gene. The genes and tissue were then hierarchically clustered using average linkage (WPGMA) (28) and Pearson correlation (29) as similarity metrics.

Testing of association between clusters and FAB classes. We performed a contingency table Chi-squared test (29) for association between clusters and FAB classes. Due to the relatively small number of samples, the samples were divided into two classes: one class containing samples with FAB class M1 and M2, and one class containing samples with FAB class M4 and M5. For each cluster, we performed a 2x2 contingency table test concerning significant high or low $\mathrm{FAB}$ representation in each cluster.

qPCR in the low density array (LDA) format. TaqMan low density arrays (LDA) are customisable, 384-well microfluidic cards for real-time PCR (Applied Biosystems). Each LDA card was configured for 95 different genes in duplicates 
including Celera gene IDs. Hexamer-primed single-stranded cDNA corresponding to $10 \mathrm{ng}$ of total RNA was diluted in TaqMan Universal buffer (Applied Biosystems) and added to each loading well. Using the above configuration each sample occupied 4-wells or one half of each card. The samples were distributed to the microwells by centrifugation for $1 \mathrm{~min}$ at $343 \times \mathrm{g}$. The cards were sealed and placed in the ABI 7900HT Sequence Detection System using the following cycling parameters: $2 \mathrm{~min}$ at $50^{\circ} \mathrm{C}, 10 \mathrm{~min}$ at $95^{\circ} \mathrm{C}$, and 40 alternate cycles of $15 \mathrm{sec}$ at $95^{\circ} \mathrm{C}$ and $60 \mathrm{sec}$ at $60^{\circ} \mathrm{C}$. SDS2.2 software was applied for relative quantitation $\left(\mathrm{RQ} / 2^{-\Delta \Delta \mathrm{Ct}}\right)$ analysis using GAPDH as normalizer and one sample as calibrator. The data were exported to Excel for further exploration and visualization.

Pathway assist analysis of molecular interactions and cellular processes. Pathway Assist is a software supplied with a molecular interaction and pathway database (ResNet), which contains 500000 links to $>50000$ proteins extracted from 5000000 Medline full-length articles. Selected genes from each cluster (C1- C3) were used as input genes in an analysis using Pathway Assist software v3.2 (www.ariadnegenomics. com) to explore and visualise biological pathways, molecular interaction and cellular processes characteristic for each cluster. The pathways were built by using three commands: i) direct interaction between input genes; ii) common targets for input genes; and iii) common regulators for input genes.

\section{Results}

Differential gene expression for each $F A B$ subclass versus the other AML samples. The gene expression profile was examined in native human AML blasts derived from 25 patients using the Human 1 cDNA Microarray from Agilent. In order to analyse the expression data for all genes, we first performed a flooring of background intensity values and calculated $\log _{2}$-ratio values based on all spots (30). We had previously found both variation and considerable overlap between gene lists based upon either floored or filtered datasets (30). A disadvantage with filtered data is the possible removal of genes that are expressed in only a minor subset of the tumors $(30,31)$. In total, 6502 out of 12814 genes were over- or under-expressed compared to the reference probe, using a one sample t-test (29) and setting the p-value threshold to 0.05 .

All arrays were selected for building a class prediction model: M1 AML (n=6), M2 AML (n=6), M4 AML (n=5), M5 AML $(n=6)$. We calculated each gene's two-sample tscore in one FAB class versus the other FAB classes, thereby identifying the genes with the most consistent high or low expression in each FAB group compared with the remaining samples. For the 100 top scoring genes the t-scores were as follows for the different FAB classes: M1 from 10.18 to 4.02 (p-values of 1.4143E-9 to 6.1389E-4), M2 from 5.31 to 3.16 (p-values of 2.8911E-5 to 4.7359E-3), M4 from 6.02 to 3.02 (p-values of 5.6065E-6 to 6.3893E-3), M5 from 4.67 to 3.11 (p-values of 1.3043E-4 to 5.3606E-3). Considering that 12814 genes were tested, we expected some genes to be high scoring by chance. We expected 7.7 genes to score higher than 4.0 , given the number of tests performed. Thus, we suspect only 8 of the 100 genes in our list for M1 to be false positives. We also expected 55 genes to score higher than 3.2, and 69.2 genes to score higher than 3.1 by chance. As a consequence of this, we expected the false discovery rate to be rather high for the gene lists for M2, M4 and M5. Still, we observe more genes than expected with high scores for these three classes.

Class prediction by use of leave-one-out crossvalidation $(L O O C V)$. In order to evaluate the ability of subsets of expressed genes to predict FAB subclass specificity, LOOCV was employed. The prediction accuracy did not increase when $>10$ genes were included (we tried 10, 20, 30, ...100). The prediction success rates were $88 \%$ for $\mathrm{M} 1,84 \%$ for $\mathrm{M} 2$ and $80 \%$ for M4 and $60 \%$ for M5 versus all other samples when 10 genes were included in the classifier. Prediction accuracy did not increase when $>10$ genes were included. It should be emphasized that, for each of the $\mathrm{n}$ test samples, new gene subsets were extracted based only upon the (n-1) training samples in each round of the LOOCV. In this way, it was avoided that information based upon the test sample was included in the classifiers. Classification of M1 versus non-M1, M2 versus non-M2, etc. gives an impression of the degree of separability of each FAB class from the other classes. This is a preliminary step to multiclass prediction, e.g. direct classification into categories M1, M2, M4 and M5.

Validation using random permutations of AML sample labels. To further test the significance of the prediction accuracies achieved using LOOCV, a permutation test was performed. The FAB labels were permuted randomly followed by LOOCV as described above. Again the design was such that information did not leak from the test samples into the classifiers, which were derived from only the training set of samples. This permutation process was repeated 1000 times for each FAB subclass in order to obtain sufficient data for estimating the distribution of prediction success on random labels. The prediction success rates achieved with randomly permuted labels were then compared with that of the original correct labelling. For M1, 981 of 1000 rounds had lower prediction accuracy than the correct labelling. Using the corresponding tests for M2, M4 and M5, 960, 922 and 812 of 1000 rounds of permuted labels, respectively, gave a lower prediction accuracy than with correctly labelled samples. The permutation results gave approximate $\mathrm{p}$-values of the prediction success rates obtained for the four FAB classes: 0.019 for M1, 0.040 for M2, 0.078 for M4 and 0.188 for M5. Thus, all class prediction success rates are higher than expected on average, although only significantly higher for M1 and M2.

Study of the 100 most differentially expressed genes for each FAB class. To investigate the correlations between FAB class labels and the expression profiles of the genes, we applied two-way hierarchical cluster analysis. The 100 genes were identified using a supervised analysis step where we calculated the $\mathrm{t}$-score of each gene, quantifying how well it separates AML samples according to the FAB classes, and selected the top 100 from the resulting list for each FAB class. The resulting dendrogram visualises the relationships between the expression profiles of these genes and how they enable separation between the FAB classes (Supplementary Fig. 1). The 100 top t-scores ranked from 10.2 to 3.1 (p-values $1.4143 \mathrm{E}-9$ to $6.3893 \mathrm{E}-3$, 


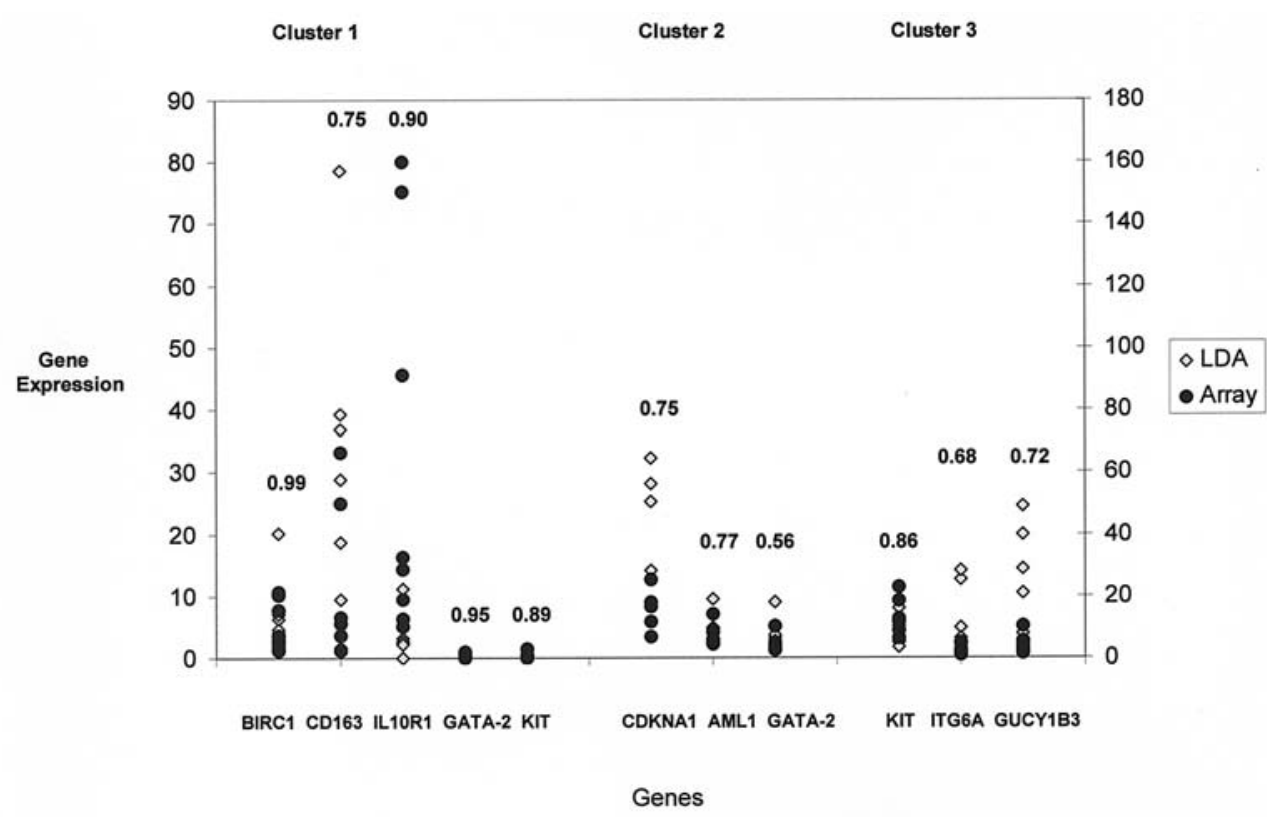

Figure 1. Correspondence between cDNA microarray and LDA gene expression. Total RNA was extracted from AML blasts and the relative mRNA expression levels were determined by qPCR TaqMan low density arrays (•, LDA) and Agilent cDNA microarrays ( $\diamond$, Array). LDA analysis used GAPDH as normalizer and one sample as calibrator. GAPDH was used for normalisation of cDNA microarray values. The correlation coefficients between Array and LDA values were calculated and visualized for each of the following genes: BIRC1, CD163, IL10R1, GATA-2, KIT (cluster 1, 8 patients); CDKNA1, AML1, GATA-2 (cluster 2, 5 patients); and KIT, ITG6A, GUCY1B3 (cluster 3, 6 patients).

respectively). In FAB M1, only $27 \%$ of the 100 genes with the highest $\mathrm{t}$-score showed overexpressed mRNAs relative to the other FAB classes. For comparison, 92\% were upregulated in $\mathrm{M} 2,77 \%$ in M4 and $43 \%$ in FAB M5. More detailed information on the most consistently differentially expressed genes between FAB classes ranked by $p$-value is shown in Supplementary Table II. GenBank accession numbers, descriptions of genes and fold changes (D) are given.

Unsupervised hierarchical cluster analysis of AML samples. Based upon the 500 genes with highest variance in the floored dataset, an unsupervised hierarchical clustering of the 25 samples generated three main clusters of AML samples and an outgroup close to clusters 2 and 3 (Supplementary Fig. 2, black). The robustness of the clusters was tested by the inclusion of various numbers of genes in the cluster analysis. The main clusters persisted although the outgroup samples redistributed in different ways when $800,500,250,100$ or 50 genes were used. LOOCV gave the samples of cluster 1 versus the other samples (Supplementary Fig. 2, blue) a prediction accuracy of $96 \%$; samples of cluster 2 versus the other samples (purple, middle of Supplementary Fig. 2), a 92\% accuracy; and samples of cluster 3 versus the other samples (red, right of Supplementary Fig. 2), a 92\% accuracy. A permutation test revealed the same success or better for randomly permuted labels for $0 / 1000$ permutations for cluster 1 and 4/1000 permutations for clusters 2 and 3 . The analysis was based upon the 50 genes with the highest t-score in the model.

Testing for association between clusters and FAB classes. A $2 \times 2$ contingency table Chi-square test did not demonstrate significant associations between FAB class and cluster 1 or cluster 2 [Chi-square values of $2.16(\mathrm{p}=0.23)$ and $1.96(\mathrm{p}=0.32)$, respectively]. The Chi-square test revealed, however, a significant association between FAB M1 and M2 samples and patient cluster $3(\mathrm{p}=0.0052)$.

Independent validation of gene expression data using realtime quantitative PCR and flow cytometry. Using the realtime quantitative PCR LDA format, 95 different genes were independently validated. In total, 17 of the genes in clusters C1-C3 were included in this analysis. The correspondence between gene expression according to the cDNA microarray (Agilent) and the quantitative PCR data (LDA) is displayed in Fig. 1. Validation of CD34 expression using flow cytometry analyses of the same samples was published previously (31).

Single genes that differed between the AML sample clusters of the unsupervised cluster analysis. In total, 76 genes exhibited a fold change between 50 and 3 for samples of one cluster compared to all other samples. In Supplementary Table III, the genes are ranked according to fold change accompanied by overall very strong p-values. Table II contains functional sorting in addition to fold change ranking. Cluster 1 samples shared a 25- to 4-fold higher expression of many immunoregulatory cytokine receptors compared to the remaining samples (Table II). Monocyte/macrophage markers, MAC- $1 \alpha$ (CD11b) and CYBB/gp91PHOX typically expressed in myeloid cells differentiated beyond the promyelocyte stage, were consistently upregulated in cluster 1. c-KIT mRNA was relatively strongly repressed in cluster 1 samples, while colony stimulating factor 1 receptor (CSF1R) that may substitute for KIT was overexpressed. TNFRSF1B forms a heterocomplex with TNF-receptor 1 and mediates the recruitment of two antiapoptotic proteins, c-IAP1 and c-IAP2. TNFRSF1B, BIRC1/ NAIP as well as MDR that mediate anti-apoptotic signals were 
Table II. Genes with altered expression in AML clusters 1-3.

\begin{tabular}{|c|c|c|c|c|c|c|c|}
\hline \multicolumn{4}{|c|}{ Altered expression of genes with important common characteristics } & \multicolumn{4}{|c|}{ Additional genes with altered expression } \\
\hline GenBank & Symbol & Gene name & $\overline{\mathrm{D}}$ & GenBank & Symbol & Gene name & $\overline{\mathrm{D}}$ \\
\hline \multicolumn{8}{|l|}{ AML cluster 1} \\
\hline \multicolumn{4}{|c|}{ Receptors and membrane molucules involved in cell signalling } & \multicolumn{4}{|c|}{ Regulation of transcription and cell cycle } \\
\hline$\uparrow$ NM_006847 & LILRB4 & Leukocyte immunoglobulin-like receptor sfB4 & 25 & & & & \\
\hline$\uparrow$ U95626 & CCRL2 & Chemokine (C-C motif) receptor-like 2 & 20 & $\uparrow$ AA573434 & KLF4 & Kruppel-like factor 4 (gut)tf & 8 \\
\hline$\uparrow \mathrm{D} 10925$ & CCR1 & Chemokine (C-C motif) receptor 1 & 17 & $\uparrow$ AA844153 & AHR & Aryl hydrocarbon receptor & 5 \\
\hline$\uparrow \mathrm{U} 20350$ & $\mathrm{CX} 3 \mathrm{CR} 1$ & Chemokine (C-X3-C motif) receptor 1 & 16 & $\uparrow$ NM_004536 & GAS7 & Growth arrest-specific 7 & 4 \\
\hline$\uparrow \mathrm{AF} 245703$ & TLR8 & Toll-like receptor 8 & 15 & ^NM_004536 & NAIP & Baculoviral IAP repeat-containing 1 & 4 \\
\hline$\uparrow$ AA402981 & KCTD12 & Voltage-sensitive potassium channel complex & 13 & $\uparrow \mathrm{M} 81934$ & $\mathrm{CDC} 25 \mathrm{~B}$ & Cell division cycle $25 \mathrm{~B}$ & 3 \\
\hline ^NM_004244 & CD163 & CD163 antigen, Scavenger receptor & 12 & $\uparrow$ U66306 & RXRA & Retinoid $\mathrm{X}$ receptor, $\alpha$ & 3 \\
\hline$\uparrow \mathrm{U} 00672$ & IL10RA & Interleukin 10 receptor, $\alpha$ & 11 & $\downarrow$ NM_006022 & $\mathrm{TSC} 22$ & TGF B-stimulated protein & 6 \\
\hline$\uparrow \mathrm{X} 04011$ & CYBB & Cytochrome b-245, ß, gp91PHOX & 10 & & & & \\
\hline$\uparrow \mathrm{Z} 82244$ & HO-1 & Heme oxygenase (decycling) 1 & 9 & & & & \\
\hline$\uparrow$ M_003264 & TLR2 & Toll-like receptor 2 & 8 & & & & \\
\hline$\uparrow \mathrm{M} 18044$ & ITGAM & MAC-1 1, CD11b (p170) & 8 & & & & \\
\hline$\uparrow \mathrm{U} 37518$ & TNFSF10 & Tumor necrosis factor (ligand) superfamily 10 & 8 & & & & \\
\hline$\uparrow$ AL034562 & PTPNS1 & Protein tyrosine phosphatase, non-receptor S1 & 6 & & & & \\
\hline$\uparrow$ M32315 & TNFRSF1B & TNFR superfamily, member 1B & 4 & & & & \\
\hline$\uparrow \mathrm{X} 03663$ & CSF1R & Colony stimulating factor 1 receptor (v-fms) & 4 & & & & \\
\hline$\uparrow Y 00081$ & IL-6 & Interleukin 6 & 3 & & & & \\
\hline$\downarrow$ NM_000222 & KIT & Stem cell factor receptor (SCFR) & 14 & & & & \\
\hline \multicolumn{8}{|l|}{ AML cluster 2} \\
\hline \multicolumn{4}{|c|}{ Regulation of transcription and cell cycle } & \multicolumn{4}{|c|}{ Membrane molecules, soluble mediators } \\
\hline$\uparrow$ M68891 & GATA-2 & GATA binding protein 2 transcription factor & 14 & $\uparrow \mathrm{J} 03745$ & MMP2 & Matrix metalloproteinase 2 & 20 \\
\hline AL031846 & $\mathrm{CBX} 7$ & Chromobox protein homolog 7 & 13 & $\downarrow$ V00522 & HLA-DR B3 & MHC, class II, DR $B 3$ & 15 \\
\hline$\uparrow \mathrm{U} 66838$ & CCNA1 & Cyclin A1 & 11 & $\downarrow$ X13334 & $\mathrm{CD} 14$ & CD14 antigen & 11 \\
\hline$\uparrow \mathrm{U} 79260$ & MGC5149 & Similar to FTO protein and MLL5 & 8 & $\downarrow$ NM_003474 & ADAM12 & A disintegrin and metalloproteinase 12 & 6 \\
\hline$\uparrow \mathrm{U} 51869$ & СРBP & Core promoter element binding protein & 5 & & & & \\
\hline$\uparrow$ AW380330 & PBXIP1 & Hematopoietic PBX-interacting protein & 4 & Others & & & \\
\hline$\uparrow$ AI825989 & ZFP36L2 & EGF-response factor 2 & 4 & $\uparrow \mathrm{M} 73720$ & СРA3 & Carboxypeptidase A3 (mast cell) & 81 \\
\hline$\uparrow \mathrm{D} 43968$ & RUNX1 & Acute myeloid leukemia 1 transcription factor & 3 & & & & \\
\hline$\downarrow$ M32011 & $\mathrm{NCF} 2$ & Neutrophil cytosolic factor 2 (gp67PHOX) & 10 & & & & \\
\hline$\downarrow$ NM_004166 & CCL15 & Chemokine (C-C motif) ligand 15 & 5 & & & & \\
\hline$\downarrow$ AA203476 & PTTG1 & Pituitary tumor-transforming 1 & 4 & & & & \\
\hline$\downarrow$ D14134 & RAD51 & DNA repair protein RAD51 homolog 1 & 3 & & & & \\
\hline$\downarrow$ Z93016 & PRG5 & p53-responsive gene 5 & 3 & & & & \\
\hline \multicolumn{8}{|l|}{ AML cluster 3} \\
\hline \multicolumn{4}{|c|}{ Soluble mediators, cell membrane receptors } & \multicolumn{4}{|c|}{ Regulation of transcription, development andcell cycle } \\
\hline$\uparrow$ AL035091 & CD34 & CD34 antigen & 15 & $\uparrow \mathrm{AB} 037762$ & MEF-2 & Myelin gene expression factor 2 & 5 \\
\hline$\uparrow \mathrm{X} 06182$ & KIT & Stem cell factor receptor (SCFR) & 4 & $\downarrow \mathrm{AB} 007854$ & GAS7 & Growth arrest-specific 7 & 3 \\
\hline$\uparrow$ M62424 & $\mathrm{F} 2 \mathrm{R}$ & Coagulation factor II (thrombin) receptor & 4 & $\downarrow$ U49278 & UBE2V1 & Ubiquitin-conjugating enzyme E2 v 1 & 3 \\
\hline$\uparrow \mathrm{AF} 186111$ & EGFL7 & EGF-like-domain, multiple 7/NEU1 & 4 & & & & \\
\hline$\uparrow$ NM_002845 & PTPRM & Protein tyrosine phosphatase, receptor type, $\mathrm{M}$ & 4 & & & & \\
\hline$\uparrow \mathrm{AB} 032994$ & CYFIP2 & p53 inducible protein & 4 & & & & \\
\hline$\uparrow \mathrm{X} 66533$ & GUCY1B3 & Guanylate cyclase 1 , soluble, B 3 & 4 & & & & \\
\hline$\uparrow$ M34667 & PLCG1 & Phospholipase $\mathrm{C}, \gamma 1$ & 3 & & & & \\
\hline$\uparrow \mathrm{X} 53586$ & ITGA6 & Integrin, $\alpha 6 / \mathrm{CD} 49 \mathrm{f}$ & 2 & & & & \\
\hline$\downarrow$ NM_080792 & PTPNS1 & Protein tyrosine phosphatase, non-receptor S1 & 5 & & & & \\
\hline$\downarrow$ NM_004119 & FLT3 & fms-related tyrosine kinase 3 & 5 & & & & \\
\hline$\downarrow$ M62880 & ITGB7 & Integrin, B 7 & 5 & & & & \\
\hline AI828515 & TNFSF13 & Tumor necrosis factor (ligand) SF13 & 5 & & & & \\
\hline
\end{tabular}

$\mathrm{D}$ is relative gene expression. 
7- to 4-fold overexpressed in this cluster. For the possible functional relationship of upregulated CD163, IL10RA, HO-1 and MDR1, see Supplementary Fig. 3 and Discussion.

Cluster 2 was characterized by upregulation $(D=2.5-14)$ of several hematopoietic transcription factors. GATA-2 $(\mathrm{D}=14)$ is ubiquitously expressed in hematopoietic cells, with particularly high expression in early hematopoietic progenitors as well as mast cell lineages, and declines with blood cell maturation (32). Other myeloid-specific factors that may enforce leukemisation are RUNX1, PBXIP. A striking feature of cluster 2 was an average 50-fold overexpression of carboxypeptidase A3, an enzyme associated with mast cell granules. The body's sole histamine-producing enzyme, histidine decarboxylase, was also highly upregulated in these samples $(D=35.0)$. EGF-2 response factor, also known as butyrate response factor 2 , is among the most consistently upregulated genes in cluster $2(\mathrm{D}=3.9)$.

Cluster 3 samples exhibited an average of 15-fold upregulation of CD34 mRNA, and 2.5- to 4-fold overexpression of integrin $\alpha 6$ (ITGA6), coagulation factor II (thrombin) receptor (F2R), and c-KIT, all membrane molecules associated with myeloid progenitor cells. As shown in the Pathway Assist-derived Supplementary Fig. 4, c-KIT and thrombin receptor F2R and CD34 may all activate the PI3K pathway and AKT1. The receptor tyrosine kinase c-KIT was relatively overexpressed and FLT3 was underexpressed, while tyrosine phosphatases PTPNS1 $(\mathrm{D}=5)$ and PTPRM $(\mathrm{D}=4)$ were overand underexpressed, respectively, in cluster 3 (Table II).

\section{Discussion}

The most important prognostic parameters in AML are currently the karyotype, genetic FLT3 abnormalities and response to the initial chemotherapy course $(3,4)$. These parameters probably mirror important parts of the complex epigenetic and genetic alterations in AML, and demonstrate that the peripheral AML cells comprise information that determines highly effective anti-leukemic treatment in a subset of the cases (20). Based on the fact that most AML patients are $>60$ years of age, and that the overall long-term survival in AML is $<50 \%$, there is a striking need for new therapeutics with more acceptable systemic toxicity (33). Our present study suggests that additional use of DNA microarrays can identify differentiation-associated gene expression patterns and define new patient subsets. The results thereby indicate that this approach may become useful for understanding the pathogenesis involved, for additional prognostic classification of patients and monitoring of differentiation induction therapy. We only included patients with high blast counts in the peripheral blood, and highly enriched AML blast populations could be prepared by density gradient separation of blood samples. This simple technique has a minimal risk of inducing functional alterations in the blasts [for a detailed discussion and additional references, see Bruserud et al (34)]. Furthermore, cells were collected, separated, frozen and thawed according to strictly standardized procedures (22).

Our patients were randomly selected from a larger group of consecutive patients with high peripheral blood blast counts (21). Our previous study demonstrated that a normal karyotype was detected for nearly $60 \%$ of our patients, whereas favourable and unfavourable karyotypes were detected only for small patient subsets (6\% and $11 \%$, respectively) (21). This distribution is similar to other studies $(3,4,35)$ except for the low frequency of favourable karyotypes that is probably due to the relatively large number of elderly patients in our study (median age 59 years) $(21,36)$. Furthermore, the higher frequencies of FLT3/ITD [40\% versus 27\%, Bruserud et al (21)] and D-835 mutations [20\% versus 7\%, Glenjen et al (37)] among our patients may reflect our selection of patients with a high degree of leukemization.

The present study found gene expression classifiers with a significant, although not very high, ability to predict FAB subclasses of AML. Both LOOCV and permutations were used to validate the prediction accuracies. Only M1 and M2 samples had expression signatures that were strong enough for use in a classification model. One biological reason may be that samples of FAB classes M1 and M2 are more homogeneous, while FAB classes M4 and M5 contain samples of more diverse gene expression. It is not unexpected that the most striking characteristic of undifferentiated AML cells (FAB-M0/M1) was downregulation of several genes involved in cell differentiation and organ development. On the other hand, granulocytic differentiation (FAB-M2) was associated with a heterogeneous gene expression pattern with regard to molecular function. In contrast, AML cells with monocytic differentiation (FAB-M4/M5) showed altered expression of genes mainly involved in intracellular signal transduction and regulation of DNA-repair, cell cycle events or DNA transcription (Supplementary Table II). This last observation is consistent with reports regarding essential regulation of gene expression during monocyte differentiation $(38,39)$. Previous studies have reported that unsupervised cluster analysis sorted AML samples according to cytogenetic abnormalities rather than FAB phenotypes (12) and that gene expression correlates with the common AML translocations $[\mathrm{t}(8 ; 21), \mathrm{t}(15 ; 17)$, inv(16)], and translocations involving 11q23 have also been described $(12,40-42)$. However, these abnormalities are uncommon, especially among the elderly majority of the consecutive population-based patient group. Even though we investigated highly heterogeneous patients randomly selected from a consecutive group with another distribution of cytogenetic abnormalities due to high age, our results are in agreement with these previous studies of relatively young selected patients: gene expression classifiers did not predict FAB subclasses with a very high accuracy but, according to t-scores, we were able to distinguish patients of a particular FAB subclass from the others.

Unsupervised hierarchical cluster analysis has a potential to reveal gene clusters shared by subsets of patient samples. This analysis is independent of previous sample classification such as FAB classification. Instead, the samples may segregate into new clusters or groups that share significant gene expression patterns. When the 500 genes with highest variance across the samples were selected for the unsupervised hierarchical cluster analysis, as visualized in Supplementary Fig. 2, three main clusters of 25 AML samples resulted. In addition, four patient samples segregated as an outgroup. LOOCV and permutation tests showed that classifiers were able to predict the three main clusters of heterogeneous AML samples with a very high accuracy. Except for a significant accumulation 
of FAB M1 and M2 samples in cluster 3, there was no evidence that the non-supervised clustering was affected by FAB subclasses. The segregation of many M1 and M2 samples into cluster 3 therefore supports the above proposal that the M1 and M2 samples of this study may share more gene expression patterns than M4 and M5 samples. It has been pointed out that the differentiation stage of the lineage, as reflected in the FAB classification, may direct unsupervised clustering to an extent that could obscure gene expression of more critical significance for prognosis and prediction (16). This idea is partly supported by the results described above. Supervised and unsupervised cluster analysis may therefore have to be supplemented by directed search and identification of expression of a number of genes that together constitute a critical regulatory module. In the future, the identification of precisely characterized modules of genes may provide the best targets for tailored treatment. We present several putatative gene expression modules.

The expression of a number of genes in clusters 1,2 and 3 (Table II and Supplementary Table III) appears relevant for the pathogenesis of AML. When several consistently regulated genes fit together into one regulatory module, the probability of functional relevance is high compared to observations on single genes. This is exemplified in cluster 1 by the relative overexpression of CD163 ( $=12)$ and IL10RA $(\mathrm{D}=10)$. Although not previously described in AML, there are several reports that CD163 and IL-10 may be involved in a regulatory loop (43-45) that leads to heme oxygenase 1 (HO-1) induction $(46,47)$. Examination of the 100 top scoring genes revealed that HO-1 is indeed consistently upregulated $(\mathrm{D}=8.6, \mathrm{p}=2.8274 \mathrm{E}-4)$ in cluster 1 samples. Recently, resistance to apoptosis has been reported in gastric cancer cells with elevated HO-1 and c-IAP2 activity (48). We noticed that NAIP/BIRC1 (IAP repeatcontaining 1 ) was also overexpressed $(\mathrm{D}=4, \mathrm{p}=7.5774 \mathrm{E}-4)$ in cluster 1 (Supplementary Fig. 3). It is therefore of interest to further explore whether the IL-10, CD163, HO-1 regulatory module has been diverted and selected to counteract terminal differentiation and apoptosis (49) and thus enhance the proliferation and survival of these AML blasts. Another pathway that may be specifically activated in this group of AML patients

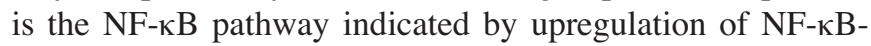
targeted genes such as ICAM-1, IL-6, TNFRSF1B and NAIP (50).

Altered expression of genes encoding transcription and chromatin condensation and cell cycle regulation factors was common for cluster 2 samples. Increased expression of the GATA-2, RUNX1, CBX7, cyclin A1 and defender against cell death 1 (DAD1) and repression of NCF2 $(\mathrm{D}=11)$ that is transcribed exclusively in myeloid cells that have differentiated beyond the promyelocyte stage, may contribute to leukemisation of hematopoietic cells with normal cytogenetics.

In cluster 3, hematopoietic stem cell marker CD34 mRNA was highly expressed. Attempts have been made to define a core gene expression pattern associated with stem cells ('stemness') $(51,52)$. This concept has met with difficulty since there is very little overlap between gene lists extracted by three different groups in order to define 'stemness' $(53,54)$. A comparison of three independently derived lists of 'stemness' genes showed only one common gene, integrin $\alpha 6$ (ITGA6), in the three studies (54). Intriguingly, this particular gene
(ITGA6, $\mathrm{p}=5.8212 \mathrm{E}-5$ ) is the second most consistently upregulated gene in cluster 3. CD34, KIT and thrombin receptor have all been associated with stem cell expression (55) and were all consistently and highly overexpressed in cluster 3 (Table II) suggesting that samples of cluster 3 share important features associated with gene expression of early myeloid precursors and possibly bone marrow stem cells (Supplementary Fig. 4).

Cluster 1 to cluster 3 subsets defined by unsupervised cluster analysis indicate that patient subpopulations may differ with regard to pathogenesis. Cluster 1 was characterized by altered expression of several soluble mediators and membrane molecules, including receptors for immunoregulatory cytokines, which may in turn activate anti-apoptotic genes and genes that mediate drug resistance. Cluster 2 (patients with normal cytogenetics) was characterized by altered expression of genes encoding the transcription/cell cycle machinery and intracellular signaling molecules. The characteristic pattern of receptor tyrosine kinase and phosphatase expression of cluster 3 samples was striking, including a prominent KIT/FLT3 (56) expression ratio in combination with downregulation of the tyrosine phosphatase PTPNS1. Such patterns may be helpful in the pursuit of new therapeutic approaches.

To conclude, our present results demonstrate that gene expression profiles can be used to: i) characterize the differentiation status of native human AML cells; and ii) define new subsets among highly heterogeneous AML patients. We suggest that supervised and unsupervised cluster analyses will have to be complemented with exact identification of regulatory gene modules that may or may not segregate into specific clusters. The new tools for global analysis of gene expression supplemented with appropriate validation and experiments have the potential to achieve this goal.

\section{Acknowledgements}

This work was funded by the Haukeland University Hospital Research Fund, the Norwegian Cancer Society, and the Olaf Ruunshaugens legat. Hua My Hoang is acknowledged for excellent technical assistance with nucleic acid labeling and hybridization. Beth Johannessen is acknowledged for excellent work with cell lines and RNA purification.

\section{References}

1. Smith M, Barnett M, Bassan R, Gatta G, Tondini C and Kern WK: Adult acute myeloid leukaemia. Crit Rev Oncol Hematol 50: 197-222, 2004.

2. Avvisati G, Lo Coco F and Mandelli F: Acute promyelocytic leukemia: clinical and morphologic features and prognostic factors. Semin Hematol 38: 4-12, 2001.

3. Wheatley K, Burnett AK, Goldstone AH, Gray RG, Hann IM, Harrison CJ, Rees JK, Stevens RF and Walker H: A simple, robust, validated and highly predictive index for the determination of risk-directed therapy in acute myeloid leukaemia derived from the MRC AML 10 trial. United Kingdom Medical Research Council's Adult and Childhood Leukaemia Working Parties. Br J Haematol 107: 69-79, 1999.

4. Kottaridis PD, Gale RE, Frew ME, Harrison G, Langabeer SE, Belton AA, Walker H, Wheatley K, Bowen DT, Burnett AK, Goldstone AH and Linch DC: The presence of a FLT3 internal tandem duplication in patients with acute myeloid leukemia (AML) adds important prognostic information to cytogenetic risk group and response to the first cycle of chemotherapy: analysis of 854 patients from the United Kingdom Medical Research Council AML 10 and 12 trials. Blood 98: 1752-1759, 2001. 
5. Harris NL, Jaffe ES, Diebold J, Flandrin G, Muller-Hermelink HK, Vardiman J, Lister TA and Bloomfield CD: World Health Organization classification of neoplastic diseases of the hematopoietic and lymphoid tissues: report of the Clinical Advisory Committee Meeting-Airlie House, VA, 1997. J Clin Oncol 17: 3835-3849, 1999

6. Golub TR, Slonim DK, Tamayo P, Huard C, Gaasenbeek M, Mesirov JP, Coller H, Loh ML, Downing JR, Caligiuri MA, Bloomfield CD and Lander ES: Molecular classification of cancer: class discovery and class prediction by gene expression monitoring. Science 286: 531-537, 1999.

7. Moos, PJ, Raetz EA, Carlson MA, Szabo A, Smith FE, Willman C, Wei Q, Hunger SP and Carroll WL: Identification of gene expression profiles that segregate patients with childhood leukemia. Clin Cancer Res 8: 3118-3130, 2002.

8. Yeoh EJ, Ross ME, Shurtleff SA, Williams WK, Patel D, Mahfouz R, Behm FG, Raimondi SC, Relling MV, Patel A, Cheng C, Campana D, Wilkins D, Zhou X, Li J, Liu H, Pui CH, Evans WE, Naeve C, Wong L and Downing JR: Classification, subtype discovery, and prediction of outcome in pediatric acute lymphoblastic leukemia by gene expression profiling. Cancer Cell 1: 133-143, 2002.

9. Armstrong SA, Staunton JE, Silverman LB, Pieters R, den Boer ML, Minden MD, Sallan SE, Lander ES, Golub TR and Korsmeyer SJ: MLL translocations specify a distinct gene expression profile that distinguishes a unique leukemia. Nat Genet 30: 41-47, 2002

10. Valk PJ, Verhaak RG, Beijen MA, Erpelinck CA, Barjesteh van Waalwijk van Doorn-Khosrovani S, Boer JM, Beverloo HB, Moorhouse MJ, van der Spek PJ, Lèowenberg B and Delwel R: Prognostically useful gene-expression profiles in acute myeloid leukemia. N Engl J Med 350: 1617-1628, 2004.

11. Bullinger L, Dèohner K, Bair E, Frèohling S, Schlenk RF, Tibshirani R, Dèohner H and Pollack JR: Use of gene-expression profiling to identify prognostic subclasses in adult acute myeloid leukemia. N Engl J Med 350: 1605-1616, 2004.

12. Debernardi S, Lillington DM, Chaplin T, Tomlinson S, Amess J, Rohatiner A, Lister TA and Young BD: Genome-wide analysis of acute myeloid leukemia with normal karyotype reveals a unique pattern of homeobox gene expression distinct from those with translocation-mediated fusion events. Genes Chromosomes Cancer 37: 149-158, 2003.

13. Yagi T, Morimoto A, Eguchi M, Hibi S, Sako M, Ishii E, Mizutani S, Imashuku S, Ohki M and Ichikawa H: Identification of a gene expression signature associated with prognosis of pediatric AML. Blood 102: 1849-1856, 2003.

14. Kohlmann A, Schoch C, Schnittger S, Dugas M, Hiddemann W, Kern W and Haferlach T: Molecular characterization of acute leukemias by use of microarray technology. Genes Chromosomes Cancer 37: 396-405, 2003.

15. Marcucci G, Mrâozek K and Bloomfield CD: Molecular heterogeneity and prognostic biomarkers in adults with acute myeloid leukemia and normal cytogenetics. Curr Opin Hematol 12: 68-75, 2005.

16. Bullinger L and Valk PJ: Gene expression profiling in acute myeloid leukemia. J Clin Oncol 23: 6296-6305, 2005.

17. Hatfield KJ, Olsnes AM, Gjertsen BT and Bruserud Ø: Antiangiogenic therapy in acute myelogenous leukemia: targeting of vascular endothelial growth factor and interleukin 8 as possible antileukemic strategies. Curr Cancer Drug Targets 5: 229-248, 2005.

18. Gjertsen BT, Øyan AM, Marzolf B, Hovland R, Gausdal G, Døskeland SO, Dimitrov K, Golden A, Kalland KH, Hood L and Bruserud $\varnothing$ : Analysis of acute myelogenous leukemia: preparation of samples for genomic and proteomic analyses. $\mathrm{J}$ Hematother Stem Cell Res 11: 469-481, 2002.

19. Bennett JM, Catovsky D, Daniel MT, Flandrin G, Galton DA, Gralnick HR and Sultan C: Proposals for the classification of the acute leukaemias. French-American-British (FAB) Cooperative Group. Br J Haematol 33: 451-458, 1976.

20. Löwenberg B, Downing JR and Burnett A: Acute myeloid leukemia. N Engl J Med 341: 1051-1062, 1999.

21. Bruserud $\varnothing$, Hovland R, Wergeland L, Huang T and Gjertsen BT: Flt3-mediated signaling in human acute myelogenous leukemia (AML) blasts: a functional characterization of Flt3-ligand effects in AML cell populations with and without genetic Flt3 abnormalities. Haematologica 88: 416-428, 2003.

22 . Bruserud $\varnothing$ : Effect of dipyridamole, theophyllamine and verapamil on spontaneous in vitro proliferation of myelogenous leukaemia cells. Acta Oncol 31: 53-58, 1992.
23. Chomczynski P and Sacchi N: Single-step method of RNA isolation by acid guanidinium thiocyanate-phenol-chloroform extraction. Anal Biochem 162: 156-159, 1987.

24. Causton HC, Quackenbush J and Brazma A: Microarray Gene Expression Data Analysis - A Beginner's Guide. Blackwell Publishing, Oxford, 2003.

25. Yang YH, Buckley MJ and Speed TP: Analysis of cDNA microarray images. Briefings Bioinformatics 2: 341-349, 2001.

26. Mardia KV, Kent JT and Bibby JM: Multivariate Analysis. Academic Press, London, p300, 1979.

27. Dysvik B and Jonassen I: J-Express: exploring gene expression data using Java. Bioinformatics 17: 369-370, 2001.

28. Sokal RR and Michener CD: A statistical method for evaluating systematic relationships. Univ Kans Sci Bull 38: 1409-1438, 1958.

29. Bhattacharyya GR and Johnson RA: Statistical Concepts and Methods. Wiley, New York, p400, 1977.

30. Halvorsen OJ, Øyan AM, B $\varnothing$ TH, Olsen S, Rostad K, Haukaas SA, Bakke AM, Marzolf B, Dimitrov K, Stordrange L, Lin B, Jonassen I, Hood L, Akslen LA and Kalland KH: Gene expression profiles in prostate cancer: association with patient subgroups and tumour differentiation. Int J Oncol 26: 329-336, 2005.

31. Øyan AM, Вø TH, Jonassen I, Ulvestad E, Gjertsen BT, Kalland $\mathrm{KH}$ and Bruserud $\varnothing$ : $\mathrm{CD} 34$ expression in native human acute myelogenous leukemia blasts: differences in CD34 membrane molecule expression are associated with different gene expression profiles. Cytometry 64: 18-27, 2005.

32. Persons DA, Allay JA, Allay ER, Ashmun RA, Orlic D, Jane SM, Cunningham JM and Nienhuis AW: Enforced expression of the GATA-2 transcription factor blocks normal hematopoiesis. Blood 93: 488-499, 1999

33. Bruserud $\varnothing$, Gjertsen BT and Huang TS: Induction of differentiation and apoptosis - a possible strategy in the treatment of adult acute myelogenous leukemia. Oncologist 5: 454-462, 2000.

34. Bruserud $\varnothing$, Gjertsen BT, Foss B and Huang TS: New strategies in the treatment of acute myelogenous leukemia (AML): in vitro culture of aml cells - the present use in experimental studies and the possible importance for future therapeutic approaches. Stem Cells 19: 1-11,2001.

35. Thiede C, Steudel C, Mohr B, Schaich M, Schèakel U, Platzbecker U, Wermke M, Bornhèauser M, Ritter M, Neubauer A, Ehninger G and Illmer T: Analysis of FLT3activating mutations in 979 patients with acute myelogenous leukemia: association with FAB subtypes and identification of subgroups with poor prognosis. Blood 99: 4326-4335, 2002.

36. Mrâozek K, Heinonen K and Bloomfield CD: Clinical importance of cytogenetics in acute myeloid leukaemia. Best practice and research. Clin Haematol 14: 19-47, 2001.

37. Glenjen N, Hovland R, Wergeland L, Wendelbo, Ernst P and Bruserud $\varnothing$ : The angioregulatory phenotype of native human acute myelogenous leukemia cells: influence of karyotype, Flt3 abnormalities and differentiation status. Eur J Haematol 71: 163-173, 2003.

38. Kowenz-Leutz E, Herr P, Niss K and Leutz A: The homeobox gene GBX2, a target of the myb oncogene, mediates autocrine growth and monocyte differentiation. Cell 91: 185-195, 1997.

39. Glynne RJ and Watson SR: The immune system and gene expression microarrays - new answers to old questions. J Pathol 195: 20-30, 2001

40. Haferlach T, Kohlmann A, Schnittger S, Dugas M, Hiddemann W, Kern W and Schoch C: Global approach to the diagnosis of leukemia using gene expression profiling. Blood 106: 1189-1198, 2005.

41. Schoch C, Kern W, Kohlmann A, Hiddemann W, Schnittger S and Haferlach T: Acute myeloid leukemia with a complex aberrant karyotype is a distinct biological entity characterized by genomic imbalances and a specific gene expression profile. Genes Chromosomes Cancer 43: 227-238, 2005.

42. Schoch C, Kohlmann A, Schnittger S, Brors B, Dugas M, Mergenthaler S, Kern W, Hiddemann W, Eils R and Haferlach T: Acute myeloid leukemias with reciprocal rearrangements can be distinguished by specific gene expression profiles. Proc Natl Acad Sci USA 99: 10008-10013, 2002.

43. Buechler C, Ritter M, Orsâo E, Langmann T, Klucken J and Schmitz G: Regulation of scavenger receptor CD163 expression in human monocytes and macrophages by pro- and antiinflammatory stimuli. J Leukoc Biol 67: 97-103, 2000. 
44. Sulahian TH, Hèogger P, Wahner AE, Wardwell K, Goulding NJ, Sorg C, Droste A, Stehling M, Wallace PK, Morganelli PM and Guyre PM: Human monocytes express CD163, which is upregulated by IL-10 and identical to p155. Cytokine 12: 1312-1321, 2000.

45. Walter RB, Bachli EB, Schaer DJ, Ruegg R and Schoedon G: Expression of the hemoglobin scavenger receptor (CD163/HbSR) as immunophenotypic marker of monocytic lineage in acute myeloid leukemia. Blood 101: 3755-3756, 2003.

46. Otterbein LE and Choi AM: Division of Pulmonary A: heme oxygenase: colors of defense against cellular stress. Am J Physiol 279: L1029-L1037, 2000

47. Philippidis P, Mason JC, Evans BJ, Nadra KM, Taylor DO, Haskard RC and Landis RC: Hemoglobin scavenger receptor CD163 mediates interleukin-10 release and heme oxygenase-1 synthesis: anti-inflammatory monocyte-macrophage responses in vitro, in resolving skin blisters in vivo, and after cardiopulmonary bypass surgery. Circ Res 94: 119-126, 2004.

48. Liu ZM, Chen GG, Ng EK, Leung WK, Sung JJ and Chung SS: Upregulation of heme oxygenase-1 and p21 confers resistance to apoptosis in human gastric cancer cells. Oncogene 23: 1-11, 2003.

49. Brouard S, Otterbein LE, Anrather J, Tobiasch E, Bach FH, Choi AM and Soares MP: Carbon monoxide generated by heme oxygenase 1 suppresses endothelial cell apoptosis. J Exp Med 192: 1015-1026, 2000.
50. Takada Y, Murakami A and Aggarwal BB: Zerumbone abolishes NF-kappaB and IkappaBalpha kinase activation leading to suppression of antiapoptotic and metastatic gene expression, upregulation of apoptosis, and downregulation of invasion. Oncogene 24: 6957-6969, 2005.

51. Ivanova NB, Dimos JT, Schaniel C, Hackney JA, Moore KA and Lemischka IR: A stem cell molecular signature. Science 298: 601-604, 2002.

52. Ramalho-Santos M, Yoon S, Matsuzaki Y, Mulligan RC and Melton DA: 'Stemness': transcriptional profiling of embryonic and adult stem cells. Science 298: 597-600, 2002.

53. Evsikov AV and Solter D: Comment on "Stemness': 'transcriptional profiling of embryonic and adult stem cells' and 'a stem cell molecular signature'. Science 302: 393, 2003.

54. Fortunel NO, Otu HH, Ng HH, Chen J, Mu X, Chevassut T, Li X, Joseph M, Bailey C, Hatzfeld JA, Hatzfeld A, Usta F, Vega VB, Long PM, Libermann TA and Lim B: Comment on ' 'Stemness': transcriptional profiling of embryonic and adult stem cells' and 'a stem cell molecular signature'. Science 302: 393, 2003.

55. Ramalho-Santos J, Schatten G and Moreno RD: Control of membrane fusion during spermiogenesis and the acrosome reaction. Biol Reprod 67: 1043-1051, 2002.

56. Care RS, Valk PJ, Goodeve AC, Abu-Duhier FM, GeertsmaKleinekoort WM, Wilson GA, Gari MA, Peake IR, Lèowenberg B and Reilly JT: Incidence and prognosis of c-KIT and FLT3 mutations in core binding factor (CBF) acute myeloid leukaemias. Br J Haematol 121: 775-777, 2003.

Supplementary Table I. Cell lines used as reference probe.

\begin{tabular}{llc}
\hline Cell lines & Tissue description & ATCC No./References \\
\hline GA-10 & B lymphocyte; Burkitt's lymphoma & CRL-2392 \\
MOLT-4 & T lymphoblast; acute lymphoblastic leukaemia & CRL-1582 \\
U-937 & Histiocytic lymphoma & CRL-1593.2 \\
ST486 & Ascites; B lymphocyte; Burkitt's lymphoma & CRL-1647 \\
K-562 & Bone marrow; chronic myelogenous leukemia (CML) & CCL-243 \\
KG-1a & Bone marrow; acute myelogenous leukaemia (AML) & CCL-246.1 \\
Jurkat $\gamma 1 . w t ~$ & T lymphocyte; acute T cell leukaemia & CRL-2679 \\
HL-60 & Peripheral blood; promyeloblast; promyeloblast; acute promyelocytic leukaemia & CCL-240 \\
MCF7 & Mammary gland; breast; epithelial; metastatic site: pleural effusion adenocarcinoma & HTB-22 \\
U-2 OS & Bone; osteosarcoma & HTB-96 \\
HEL 299 & Lung; fibroblast; normal & CCL-137 \\
HeLa & Cervix; epithelial; adenocarcinoma & CCL-2 \\
Placenta & Human placenta; normal & a \\
HUV-EC-C & Umbilical vein; vascular endothelium; endothelial; normal & b \\
SaOS-2 & Bone; osteosarcoma & HTB-85 \\
RF-48 & Stomach; metastatic site: ascites gastric adenocarcinoma & CRL-1863 \\
NCI-N87 & Stomach; metastatic site: liver gastric carcinoma & CRL-5822 \\
HLF-a & Lung; epidermoid carcinoma & CCL-199
\end{tabular}

abtained from Professor Helga Salvesen, Haukeland University Hospital. ${ }^{\text {} H U V E C ~ c e l l ~ l i n e ~ w a s ~ m a d e ~ b y ~ T h e r e s e ~ V i s t e d, ~ U n i v e r s i t y ~ o f ~}$ Bergen (e-mail: therese.visted@pki.uib.no). 


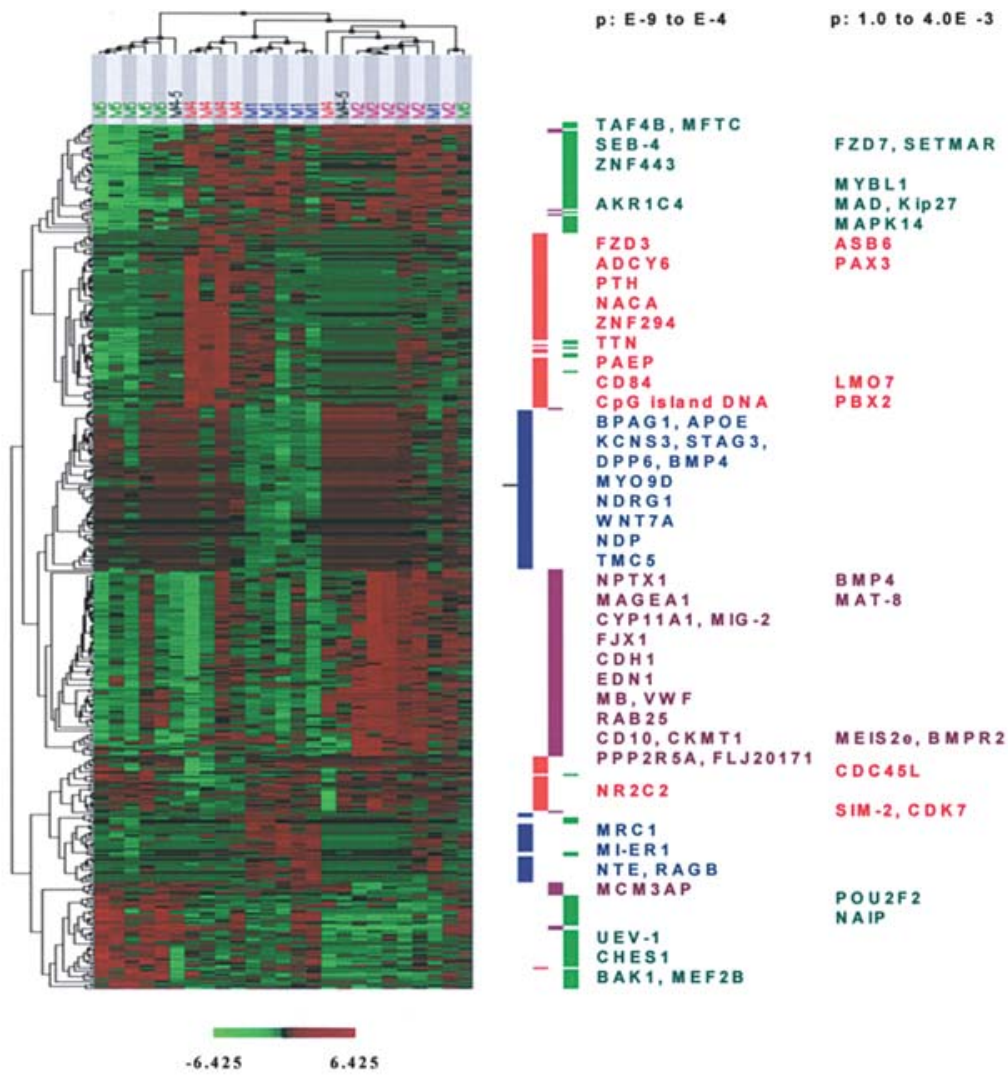

Supplementary Figure 1. Two-way cluster analysis of AML samples. Supervised two-way cluster analysis based upon 100 genes with top t-scores discriminating patients of FAB classes M1 (blue), M2 (violet), M4 (red) and M5 (green). The two samples classified as FAB M4-5 are included in the two-way cluster analysis (black). The corresponding p-values of the genes characteristically expressed in M1, M2. M4 and M5 ranged from 1.4143E-9 to 6.3893E-3. Gene clusters are indicated by vertical bars and a few selected genes of each cluster were extracted and highlighted in the same colour.

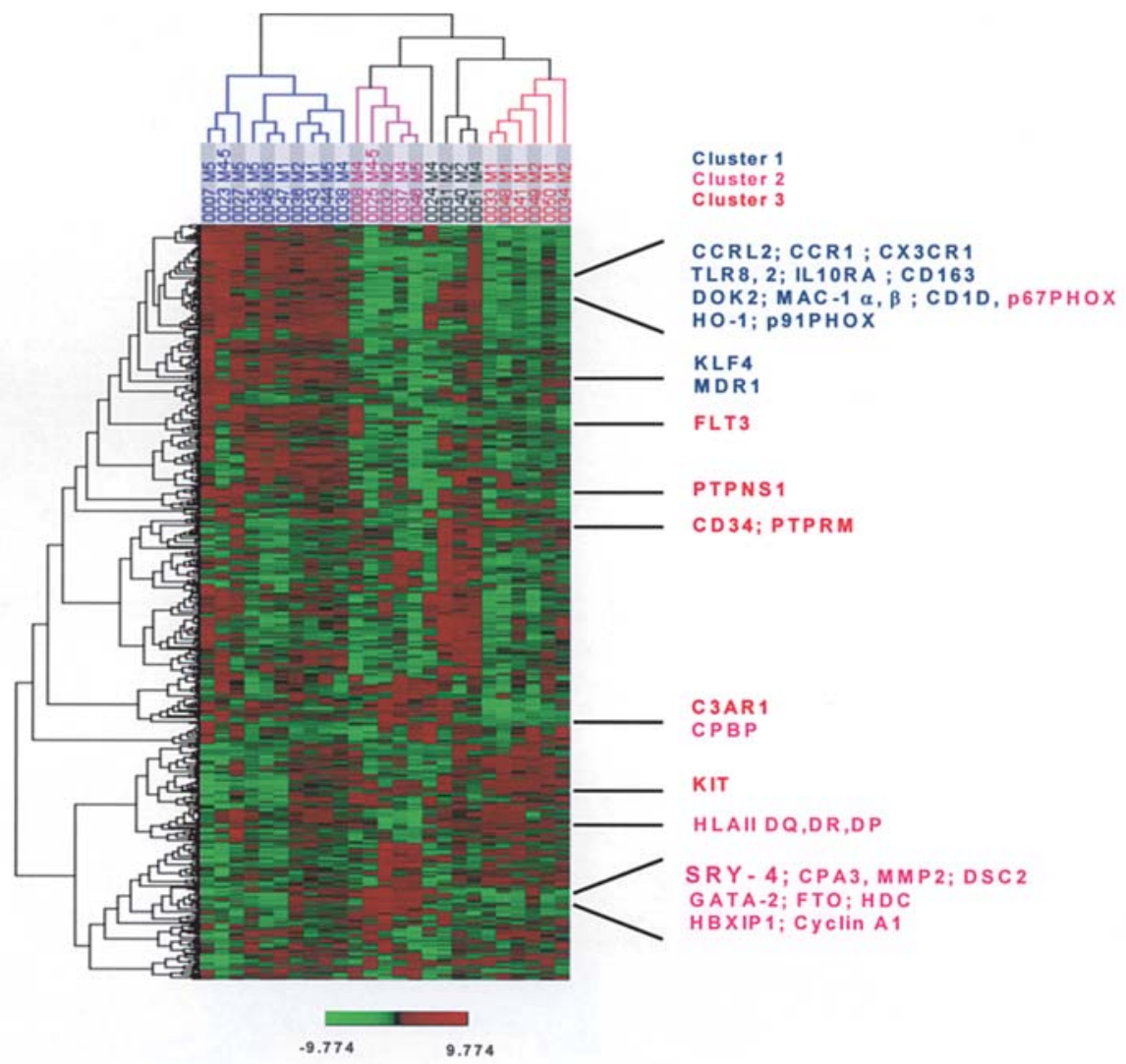

Supplementary Figure 2. Unsupervised two dimensional hierarchical cluster analysis of gene expression in AML. Unsupervised two dimensional hierarchical cluster analysis of different FAB classes based upon 500 of 12814 genes with highest variance. The clustering defines three sample clusters: cluster 1 (blue), cluster 2 (purple), cluster 3 (red). The gene profiles were centered by subtracting the mean before clustering. Characteristic genes of each cluster are indicated to the right. 
Supplementary Table II. Genes that separate the AML FAB classes.

A GenBank Gene symbol

Gene name

Relative gene expression p-value

$\mathrm{D}$

Genes overexpressed in M1

$\begin{array}{ll}\text { AK024443 } & \text { NTE } \\ \text { NM_006064 } & \text { RAGB } \\ \text { X93093 } & \text { ICAM4 } \\ \text { X87344 } & \text { MDR/TAP } \\ \text { AB046830 } & \text { MI-ER1 } \\ \text { X91826 } & \text { ZNF75a } \\ \text { M84337 } & \text { PAP } \\ \text { M93215 } & \text { MRC1 }\end{array}$

Similar to neuropathy target esterase, anti apoptotic

3.0

GTP-binding protein ragB

Intercellular adhesion molecule 4

Transporter 2, ATP-binding cassette, sub-family B

Mesoderm induction early response

Pancreatitis-associated protein

Mannose receptor, $\mathrm{C}$ type 1

Genes underexpressed in M1

$\begin{array}{ll}\text { J03202 } & \text { LAMC1 } \\ \text { AW843848 } & \text { PLA2G2A } \\ \text { AF196481 } & \text { MID2 } \\ \text { AW971101 } & \text { ARHGAP8 } \\ \text { D87953 } & \text { NDRG1 } \\ \text { NM_002252 } & \text { KCNS3 } \\ \text { U53476 } & \text { WNT7A } \\ \text { U42391 } & \text { MYO9B } \\ \text { AB011103 } & \text { KIF5C } \\ \text { NM_002387 } & \text { MCC } \\ \text { AW160589 } & \text { APOE } \\ \text { NM_006489 } & \text { NOVA1 } \\ \text { AL035702 } & \text { RASAL1 } \\ \text { L33404 } & \text { KLK7 } \\ \text { AB009849 } & \text { KLK8 } \\ \text { AI572906 } & \text { STAG3 } \\ \text { M69225 } & \text { BPAG1 } \\ \text { AK023655 } & \text { TMC5 } \\ \text { U43842 } & \text { BMP4 } \\ \text { M96860 } & \text { DPP6 } \\ \text { NM_000266 } & \text { NDP }\end{array}$

Laminin, $\gamma 1$

Phospholipase A2, group IIA

Midline 2

Rho GTPase activating protein 8

$\mathrm{N}$-myc downstream regulated gene 1

Potassium voltage-gated channel

Proto-oncogene Wnt7a

Myosin IXB

Kinesin family member 5C

Mutated in colorectal cancers

Apolipoprotein E

Neuro-oncological antigen 1

RAS protein activator like 1

Kallikrein 7 (stratum corneum)

Kallikrein 8

Stromal antigen 3

Bullous pemphigoid antigen1

Transmembrane channel-like 5

Bone morphogenetic protein 4

Dipeptidylpeptidase 6

Norrie disease (pseudoglioma)

$3.7247 \mathrm{E}-4$
$1.9828 \mathrm{E}-4$
$1.6744 \mathrm{E}-4$
$3.9473 \mathrm{E}-4$
$2.0080 \mathrm{E}-4$
$1.3696 \mathrm{E}-4$
$4.9653 \mathrm{E}-4$
$1.9629 \mathrm{E}-6$

3.9831E-4

3.6911E-4

4.8791E-4

$5.8626 \mathrm{E}-6$

$5.4704 \mathrm{E}-6$

$1.2604 \mathrm{E}-5$

$3.7536 \mathrm{E}-5$

$1.0559 \mathrm{E}-5$

$3.4434 \mathrm{E}-5$

$2.4439 \mathrm{E}-4$

$2.7438 \mathrm{E}-7$

$1.9385 \mathrm{E}-5$

$1.7686 \mathrm{E}-4$

$9.3908 \mathrm{E}-6$

$1.8622 \mathrm{E}-7$

$1.0456 \mathrm{E}-5$

$1.4143 \mathrm{E}-9$

$1.3093 \mathrm{E}-6$

$2.3826 \mathrm{E}-4$

4.2772E-6

8.0898E-9

Genes overexpressed in M2

$\begin{array}{ll}\text { AW269972 } & \text { TSPAN-2 } \\ \text { AK000996 } & \text { DNAPTP4 } \\ \text { Z24725 } & \text { MIG-2 } \\ \text { J04469 } & \text { CKMT1 } \\ \text { AF080071 } & \text { CTNNAL1 } \\ \text { S56805 } & \text { EDN1 } \\ \text { L34789 } & \text { CDH1 } \\ \text { AA143153 } & \text { CYP11A1 } \\ \text { X52003 } & \text { TFF1 } \\ \text { AK000178 } & \text { FLJ20171 } \\ \text { U82671 } & \text { MAGEA1 } \\ \text { NM_002522 } & \text { NPTX1 } \\ \text { AI219825 } & \text { CDH1 } \\ \text { AJ245599 } & \text { FJX1 } \\ \text { NM_005368 } & \text { MB } \\ \text { AF083124 } & \text { RAB25 } \\ \text { X04385 } & \text { VWF } \\ \text { M26628 } & \text { MME } \\ \text { NM_001204 } & \text { BMPR2 } \\ \text { U28249 } & \text { MAT-8 } \\ \text { M22490 } & \text { BMP4 } \\ \text { AF179896 } & \text { MEIS2e } \\ \text { AJ222700 } & \text { TSC22 } \\ \text { AA234460 } & \text { PPP2R5A }\end{array}$

Tetraspan 2

0.0020256

DNA pol transactivated protein 4

Pleckstrin homology domain containing C1

$3.1239 \mathrm{E}-4$

Creatine kinase, mitochondrial 1 (ubiquitous)

Catenin (cadherin-associated protein), $\alpha$-like 1

$5.5451 \mathrm{E}-4$

Endothelin 1

E-cadherin

Cytochrome P450, 11 sf A1

Trefoil factor 1

Hypothetical nucleic acid binding protein

Melanoma antigen, family A, 1

Neuronal pentraxin I

E-cadherin (epithelial)

Four jointed box 1 (Drosophila)

Myoglobin

RAB25, member of RAS oncogene family

Von Willebrand factor

Membrane metallo-endopeptidase/CD10

5.7904E-4

0.0024472

$2.6668 \mathrm{E}-4$

$3.0812 \mathrm{E}-4$

$1.2900 \mathrm{E}-4$

0.0015604

$1.0714 \mathrm{E}-4$

$6.3487 \mathrm{E}-4$

$4.1349 \mathrm{E}-4$

$1.4154 \mathrm{E}-4$

$8.7494 \mathrm{E}-5$

$9.8454 \mathrm{E}-5$

$1.0446 \mathrm{E}-4$

$2.4684 \mathrm{E}-4$

$2.7408 \mathrm{E}-4$

Bone morphogenetic protein receptor, type II

0.0012506

Mammary tumor protein 8

Bone morphogenetic protein 4

Meis 1, myeloid ecotropic viral int 1 homolog 2

0.0022710

0.0025805

Transforming growth factor $\beta$-stimulated

0.0037418

Protein phosphatase 2, regulatory subunit B (B56)

0.0023206

$1.1564 \mathrm{E}-4$ 
Supplementary Table II. Continued.

\begin{tabular}{|c|c|c|c|c|}
\hline $\begin{array}{l}\text { A } \\
\text { GenBank }\end{array}$ & Gene symbol & Gene name & $\begin{array}{c}\text { Relative gene expression } \\
\text { D }\end{array}$ & p-value \\
\hline \multicolumn{5}{|c|}{ Genes underexpressed in M2 } \\
\hline AA993270 & RNASE6 & RNase A k6 & 8.0 & 0.0042152 \\
\hline AI828515 & TNFSF13 & Tumor necrosis factor (ligand) superfamily, 13 & 6.0 & 0.0041853 \\
\hline NM_003906 & MCM3AP & Minichromosome maintenance deficient 3 & 1.8 & 0.0010823 \\
\hline
\end{tabular}

$\mathrm{B}$

GenBank Gene symbol

Gene name

Relative gene expression p-value

D

Genes overexpressed in M4

Z62661

U02368

PAX3

AL137735

ABS2

AK000555 ASB6

AA777749 LMO7

F17759 GPD1

X59842 PBX2

V00597 PTH

AF141882 APMCF1

AA779336 C4BPB

AL163248 ZNF294

X90568

TTN

NM_003874 CD84

M34046 PAEP

AB002361

KIAA0363

AF250226

ADCY6

AP000500

AB039723

FZD3

AF155104

MED6

Genes underexpressed in M4

$\begin{array}{ll}\text { U80456 } & \text { SIM2 } \\ \text { U10990 } & \text { NR2C2 } \\ \text { AF081535 } & \text { CDC45L } \\ \text { X77743 } & \text { CDK7 }\end{array}$

Genes overexpressed in M5

AK027180 MEF2D

NM_004536 NAIP

BE271713 PTPN18

NM_002698 POU2F2

AI741331 BAK1

U68723 CHES1

U49278 UEV-1

Genes underexpressed in M5

AK001241 FLJ10379

S68287 AKR1C4

AB046663 MFTC

U59912 MAD

L35263 MAPK14

AA761901 MYBL1

AF054989 SETMAR

Y09321 TAF4B

AAF81070 SEB-4

AB011414 ZNF443

AB017365 FZD7

AA455410 CDKN4
CpG island DNA genomic Mse1 fragment

Paired box gene 3

Ankyrin repeat and SOCS box-containing 2

Ankyrin repeat and SOCS box-containing 6

LIM domain only 7

Glycerol-3-phosphate dehydrogenase 1

Pre-B-cell leukemia transcription factor 2; HOX12

Parathyroid hormone

3.3

3.1

3.0

3.0

2.8

2.6

2.5

2.4

Signal recognition particle receptor

2.4

Complement component 4 binding protein, $B$

Zinc finger protein 294

Titin

CD84 antigen

Progestagen-associated endometrial protein

Similar to $\alpha$ NAC protein, NACA

Adenylate cyclase 6

Chromosome 3p21.3, anti-oncogene region

Frizzled homolog 3

Mediator of RNA polymerase II transcription, S6 homolog

Single-minded homolog 2

Nuclear receptor subfamily 2,C

Cell division cycle 45-like

Cyclin-dependent kinase 7

2.3

2.3

2.3

2.3

2.1

2.1

2.0

1.8

1.4

1.4

3.5

3.3

3.2

2.7

MADS box transcription enhancer factor 2

5.5

Baculoviral IAP repeat-containing 1

Protein tyrosine phosphatase

POU domain, class 2, transcription factor

BCL2-antagonist/killer 1

Checkpoint suppressor 1

Ubiquitin-conjugating enzyme E2 variant 1

Hypothetical protein FLJ10379

Aldo-keto reductase family 1 , member C4

Mitochondrial folate transporter/carrier

MAX dimerization protein 1

Mitogen-activated protein kinase 14

v-myb myeloblastosis viral oncogene like 1

SET domain and mariner transposase fusion gene

TATA-binding protein associated factors

Similar to ssDNA binding protein SEB4

Kruppel-type zinc finger (C2H2)

Frizzled homolog 7, Frizzled receptor

Cyclin-dependent kinase inhibitor 1B (Kip1, p27)
7.0084E-4

0.0043684

0.0027760

0.0011355

0.0022797

$8.5218 \mathrm{E}-6$

0.0044071

4.2872E-4

4.0106E-4

$5.3546 \mathrm{E}-5$

1.7194E-4

2.0182E-4

$2.8752 \mathrm{E}-4$

7.5400E-5

2.3867E-4

1.4458E-4

$2.4579 \mathrm{E}-4$

9.2867E-4

3.2020E-4

0.0022416

$5.6064 \mathrm{E}-6$

0.0011646

0.0039741

5.2806E-4

0.0037580

0.0016970

0.0015483

1.3042E-4

$1.9165 \mathrm{E}-4$

9.4665E-4

0.0015801

9.2731E-4

4.8732E-4

0.0038577

0.0013878

0.0013150

0.0013803

$4.5509 \mathrm{E}-4$

5.3294E-4

7.3397E-4

0.0037855

0.0026842

$\mathrm{D}$ is relative gene expression. 
Supplementary Table III.

A, Differential expressed genes in AML cluster 1 (C1)

GenBank Gene symbol

Gene name

Relative gene expression p-value

D

Genes overexpressed in $\mathrm{C} 1$

LILRB4

U95626 CCRL2

D10925 CCR1

U20350 CX3CR1

AF245703 TLR8

AA402981 KCTD12

NM_004244 CD163

AX017610 WO9947655

AF012281 PDZD1

U00672 IL10RA

J04142 CD1D

X04011 CYBB

M87842 LGALS2

Z82244 HO-1

J03745 ANX5

NM_003264 TLR2

U37518 TNFSF10

AA573434 KLF4

M18044 ITGAM

AW015376 NCF1

X83289 MDR1/ABCB1

AF282618

X78947

RISC

AL034562

CTGF

AF034970

PTPNS1

BE293414

DOK2

AA844153 AHR

X03663 CSF1R

M32315 TNFRSF1B

NM_004536 NAIP

M15395 ITGB2

AB007854 GAS7

U66306 RXRA

M81934 CDC25B

Y00081 IL-6
Leukocyte immunoglobulin-like receptor sfB 4

Chemokine (C-C motif) receptor-like 2

Chemokine (C-C motif) receptor 1

Chemokine (C-X3-C motif) receptor 1

Toll-like receptor 8

Potassium channel tetramerisation domain containing 12

CD163 antigen, Scavenger receptor

Similar to CD20-like precusor mRNA

PDZ domain containing 1

Interleukin 10 receptor, $\alpha$

CD1D antigen, $d$ polypeptide

Cytochrome b-245, $\beta$ polypeptide, gp91phox

Lectin, galactoside-binding, soluble, 2

Heme oxygenase (decycling) 1

Annexin A5

Toll-like receptor 2

Tumor necrosis factor (ligand) superfamily 10

Kruppel-like factor 4 (gut) transcription factor

MAC-1 $\alpha$, CD11b (p170)

Neutrophil cytosol factor 1

Multidrug resistance 1

Retinoid-inducible serine carboxypeptidase

Connective tissue growth factor

Protein tyrosine phosphatase, non-receptor S1

Docking protein 2

Annexin A2

Aryl hydrocarbon receptor

Colony stimulating factor 1 receptor ( $\mathrm{v}-\mathrm{fms}$ )

TNFR superfamily, member 1B

Baculoviral IAP repeat-containing 1

MAC-1ß, CD18

Growth arrest-specific 7

Retinoid X receptor, $\alpha$

Cell division cycle 25B

Interleukin 6

25.0

20.0

20.0
16.9

16.4

14.8

13.9

12.0

11.8

11.1

10.6

10.5

10.4

9.9

8.6

8.3

8.0

8.1

8.1

7.9

7.6

7.5

7.0

6.9

6.0

6.0

5.7

5.1

4.5

4.3

4.3

3.7

3.6

3.2

3.0

2.5

Stem cell factor receptor (SCFR)

14.3

11.9

Ras homolog gene family, member $\mathrm{H}$

SRY (sex determining region Y)-box 4

TGF ß-stimulated protein
Integral membrane protein $2 \mathrm{~A}$

$6.0010 \mathrm{E}-5$

$2.1689 \mathrm{E}-5$

$2.7644 \mathrm{E}-6$

$5.7489 \mathrm{E}-6$

5.8377E-7

$3.1412 \mathrm{E}-5$

$3.7383 \mathrm{E}-5$

4.0021E-4

$1.6133 \mathrm{E}-5$

$1.4853 \mathrm{E}-4$

$9.9480 \mathrm{E}-6$

$1.1829 \mathrm{E}-4$

$2.5241 \mathrm{E}-6$

$3.3551 \mathrm{E}-4$

3.1703E-5

$1.4047 \mathrm{E}-4$

$3.6638 \mathrm{E}-5$

$3.8469 \mathrm{E}-4$

4.3479E-4

$1.9885 \mathrm{E}-4$

$1.4778 \mathrm{E}-4$

8.2971E-5

$1.6649 \mathrm{E}-4$

$6.2263 \mathrm{E}-6$

$4.9222 \mathrm{E}-5$

3.4704E-7

$3.5884 \mathrm{E}-5$

$2.3262 \mathrm{E}-4$

$6.8904 \mathrm{E}-5$

$8.6550 \mathrm{E}-4$

$2.0915 \mathrm{E}-4$

$5.8188 \mathrm{E}-4$

$3.0909 \mathrm{E}-4$

$2.0141 \mathrm{E}-4$

$1.6578 \mathrm{E}-4$

Genes underexpressed in $\mathrm{C} 1$

$\begin{array}{ll}\text { AI819896 } & \text { ITM2A } \\ \text { Z35227 } & \text { ARHH } \\ \text { X70683 } & \text { SOX4 } \\ \text { NM_006022 } & \text { TSC22 }\end{array}$

B, Differential expressed genes in AML cluster 2 (C2)

GenBank Gene symbol

Gene name

Relative gene expression

p-value
$5.2996 \mathrm{E}-5$

$3.6744 \mathrm{E}-4$

$8.8347 \mathrm{E}-5$

$1.9885 \mathrm{E}-4$

$5.5508 \mathrm{E}-5$

$\begin{array}{ll}\text { Genes overexpressed in C2 } \\ \text { M73720 } & \text { CPA3 } \\ \text { M27717 } & \text { CPA3 } \\ \text { M60445 } & \text { HDC } \\ \text { J03210 } & \text { MMP2 } \\ \text { AI133467 } & \text { DSC2 } \\ \text { AW873072 } & \text { DSC2 } \\ \text { M68891 } & \text { GATA-2 } \\ \text { AL031846 } & \text { CBX7 } \\ \text { U66838 } & \text { CCNA1 } \\ \text { U79260 } & \text { FTO } \\ \text { D25217 } & \text { MLC1 } \\ \text { U51869 } & \text { CPBP }\end{array}$

Carboxypeptidase A3 (mast cell)

Carboxypeptidase A3 (mast cell)

Histidine decarboxylase

Matrix metalloproteinase 2

Desmocollin 2

Desmocollin 2

GATA binding protein 2 transcription factor

Chromobox protein homolog 7

Cyclin A1

Fatso

Megalencephalic leukoencephalopathy

Similar to core promoter element binding protein
81.8

50.0

35.0

20.1

19.0

14.8

14.5

13.0

11.3

7.8

7.5

5.5

D 
Supplementary Table III. Continued. B, Differential expressed genes in AML cluster $2(\mathrm{C} 2)$
GenBank Gene symbol
Gene name
Relative gene expression $\quad$-value

\begin{tabular}{ll}
\hline \multicolumn{3}{c}{ Genes overexpressed in C2 } \\
AW380330 & PBXIP1 \\
AI825989 & ZFP36L2 \\
M61906 & PIK3R1 \\
D43968 & RUNX1 \\
U84214 & DAD1
\end{tabular}

Genes underexpressed in $\mathrm{C} 2$

\begin{tabular}{ll} 
V00522 & HLA-DRB3 \\
M14662 & HLA-DRB1 \\
X00457 & HLA-DRA1 \\
NM_000433 & NCF2 \\
X13334 & CD14 \\
J03745 & ANXA5 \\
M32011 & NCF2 \\
J03745 & ANX5 \\
M24364 & HLA-DQB1 \\
AI765830 & BLVRA \\
D14665 & ADAM9 \\
M23254 & CANP2 \\
NM_003474 & ADAM12 \\
M26038 & HLA-DRB3 \\
BE244440 & HLA-DRA \\
NM_004166 & CCL15 \\
AA203476 & PTTG1 \\
AK001323 & ECT2 \\
D14134 & RAD51 \\
Z93016 & WAP1 \\
\hline
\end{tabular}

Hematopoietic PBX-interacting protein

EGF-response factor 2

Phosphoinositide-3-kinase, regulatory subunit 1

Acute myeloid leukemia 1 transcription factor

Defender against cell death 1
$9.0979 \mathrm{E}-4$

8.2812E-4

$1.8857 \mathrm{E}-4$

$2.4381 \mathrm{E}-4$

$5.2159 \mathrm{E}-5$

Major histocompatibility complex, class II, DR B3

Major histocompatibility complex, class II, DR B1

$1.6546 \mathrm{E}-4$

Major histocompatibility complex, class II, DP $\alpha 1$

$2.3413 \mathrm{E}-4$

$3.5939 \mathrm{E}-4$

0.0010103

$8.4406 \mathrm{E}-4$

CD14 antigen

Annexin V

Neutrophil cytosolic factor 2 (p67PHOX)

Annexin A5

Major histocompatibility complex, class II, DQ B1

$3.1472 \mathrm{E}-4$

$5.6149 \mathrm{E}-4$

$3.1472 \mathrm{E}-4$

$1.6546 \mathrm{E}-4$

$3.3305 \mathrm{E}-4$

0.0010558

$8.0661 \mathrm{E}-4$

4.6973E-5

$1.4960 \mathrm{E}-4$

$1.6802 \mathrm{E}-4$

$7.0302 \mathrm{E}-5$

4.6634E-4

0.0010097

0.0010610

$8.6981 \mathrm{E}-4$

C, Differential expressed genes in AML cluster 3 (C3)

GenBank Gene symbol

Gene name

Relative gene expression $\quad \mathrm{p}$-value

D

\begin{tabular}{|c|c|c|c|c|}
\hline \multicolumn{5}{|c|}{ Genes overexpressed in C3 } \\
\hline AL035091 & CD34 & CD34 antigen & 15.0 & 3.3273E-4 \\
\hline M86609 & AKR1C1 & Aldo-keto reductase $\mathrm{C}$ & 6.3 & $6.4644 \mathrm{E}-6$ \\
\hline AB037762 & MEF-2 & Myelin gene expression factor 2 & 4.5 & $8.4979 \mathrm{E}-5$ \\
\hline S68287 & AKR1C1 & Aldo-keto reductase $\mathrm{C}$ & 4.3 & $5.9716 \mathrm{E}-5$ \\
\hline M62424 & $\mathrm{F} 2 \mathrm{R}$ & Coagulation factor II (thrombin) receptor & 4.2 & $2.3010 \mathrm{E}-4$ \\
\hline X66533 & GUCY1B3 & Guanylate cyclase 1 , soluble, $\beta 3$ & 4.0 & $3.0817 \mathrm{E}-4$ \\
\hline AI678022 & PTPRM & Protein tyrosine phosphatase, receptor type, M & 4.0 & $3.4608 \mathrm{E}-4$ \\
\hline X06182 & KIT & Stem cell factor receptor (SCFR) & 3.9 & 0.0019252 \\
\hline AF186111 & EGFL7 & EGF-like-domain, multiple 7/NEU1 & 3.6 & 0.0031686 \\
\hline AA100426 & MOX2 & OX-2 membrane glycoprotein precursor & 3.3 & 0.0021809 \\
\hline U96922 & NPP4B & Inositol polyphosphate-4-phosphatase, type II & 3.1 & $1.8965 \mathrm{E}-4$ \\
\hline M34667 & PLCG1 & Phospholipase $\mathrm{C}, \gamma 1$ & 2.7 & 0.0014567 \\
\hline X53586 & ITGA6 & Integrin, $\alpha 6 / \mathrm{CD} 49 \mathrm{f}$ & 2.3 & 7.4027E-5 \\
\hline \multicolumn{5}{|c|}{ Genes underexpressed in $\mathrm{C} 3$} \\
\hline M62880 & ITGB7 & Integrin, $B 7$ & 5.2 & 0.0010669 \\
\hline AI828515 & TNFSF13 & Tumor necrosis factor (ligand) superfamily, 13 & 5.1 & 0.0024154 \\
\hline NM_004119 & FLT3 & Fms-related tyrosine kinase 3 & 4.8 & 0.0024840 \\
\hline AL034562 & PTPNS1 & Protein tyrosine phosphatase, non-receptor S1 & 4.6 & $3.4608 \mathrm{E}-4$ \\
\hline U02687 & FLT3 & Fms-related tyrosine kinase 3 & 4.4 & 0.0024840 \\
\hline D00017 & ANXA2 & Annexin A2 & 3.5 & 0.0024005 \\
\hline AB007854 & GAS7 & Growth arrest-specific 7 & 3.2 & 0.0018785 \\
\hline U13697 & CASP1 & Caspase 1 & 3.0 & 0.0025037 \\
\hline AX011749 & WO9955858 & Similar to AHNAK & 3.0 & $1.3911 \mathrm{E}-6$ \\
\hline U49278 & UBE2V1 & Ubiquitin-conjugating enzyme E2 variant 1 & 2.8 & $2.5605 \mathrm{E}-4$ \\
\hline
\end{tabular}

$\mathrm{D}$ is relative gene expression. 


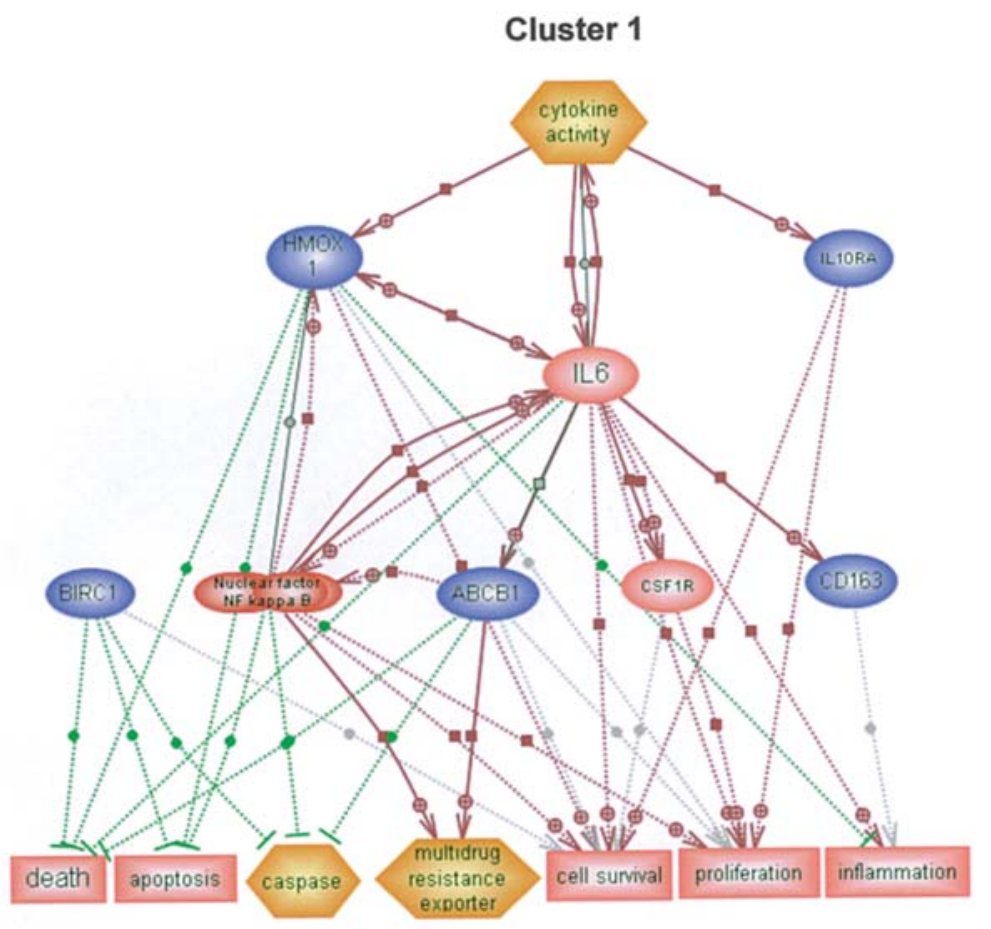

Supplementary Figure 3. Analysis of molecular interactions and cellular processes using Pathway Assist. Highly expressed genes in cluster 1 (C1), supposed to be involved in a regulatory loop that lead to heme oxygenase 1 induction, were used as input genes (blue) for analysis. Three genes, CD163, BIRC1 and IL10RA, were validated using QPCR LDA. The common regulator for these genes selected by Pathway Assist was IL-6 (pink) or the functional class cytokines (yellow). Both IL-6 and other cytokines and CSF1R (v-fms) were represented among the most differentially overexpressed genes in C1. Red lines, positive effect; green lines, negative effect; gray dotted lines, effect of unknown function; grey solid lines, a direct binding between HMOX1 and NF-kB complex.

\section{Cluster 3}

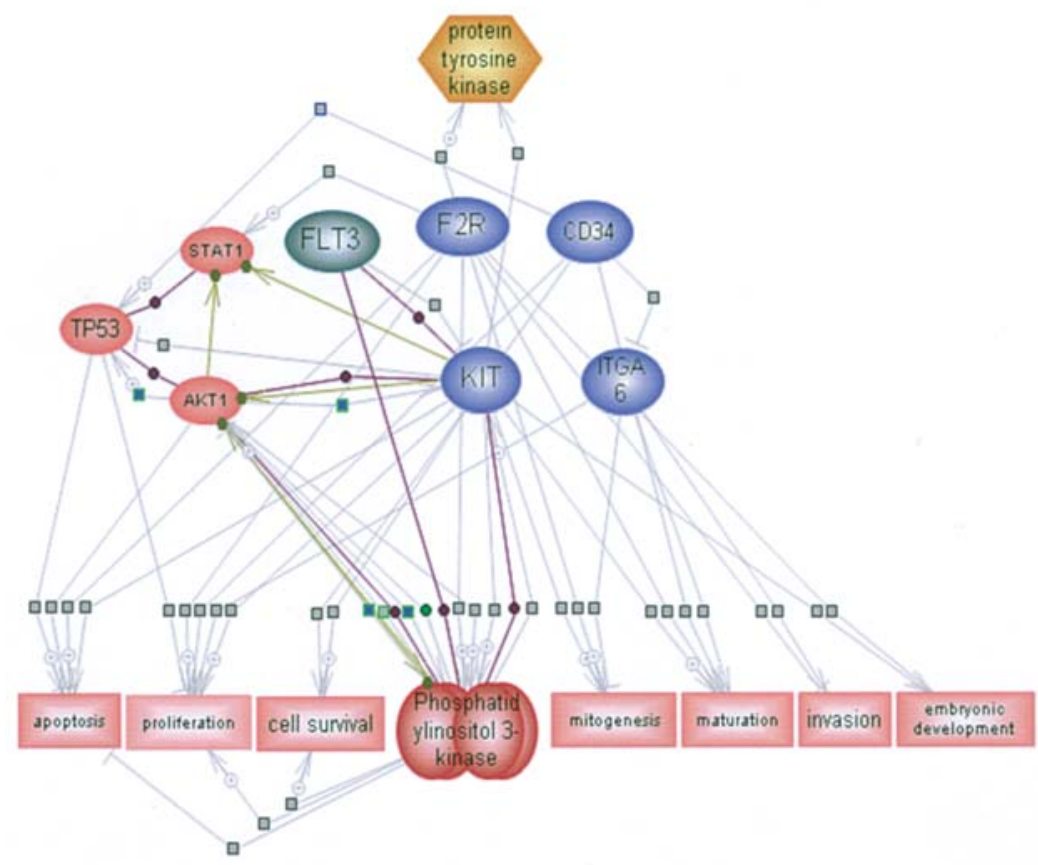

Supplementary Figure 4. Networks of molecular interactions and cellular processes activated in cluster 3 using CD34, c-KIT, F2R and ITGA6 as input genes. CD34, c-KIT, F2R and ITGA6 (blue) are membrane molecules characteristic of myeloid progenitor cells and were highly expressed in this cluster, while FLT3 (green) was underexpressed. The expression profile of the genes was mainly controlled with QPCR LDA. CD34 has previously been validated using flow cytometry (31). Downstream targets for the selected genes were p53, AKT1, STAT1 (pink) and PI3-kinase (PI3K) complex. Lines with arrows, positive effect; violet lines, protein-protein binding; green lines, protein modification; blue square on the line between CD34 and TP53, positive effect of CD34 on molecular synthesis of p53; green square, positive effect on gene expression; line with green circle, possibility for PI3K to bind to the AKT1 promoter. 